Published in final edited form as:

ACS Nano. 2016 October 25; 10(10): 9274-9286. doi:10.1021/acsnano.6b03409.

\title{
Switching the Immunogenicity of Peptide Assemblies Using Surface Properties
}

\author{
Yi Wen ${ }^{1,2}$, Amelia Waltman², Huifang Han², and Joel H. Collier ${ }^{1,2,{ }^{*}}$ \\ ${ }^{1}$ Duke University, Biomedical Engineering Department, Durham, NC 27708, USA \\ ${ }^{2}$ University of Chicago, Department of Surgery, Chicago, IL 60637, USA
}

\begin{abstract}
Biomaterials created from supramolecular peptides, proteins, and their derivatives have been receiving increasing interest for both immunological applications such as vaccines and immunotherapies, as well as ostensibly non-immunological applications such as therapeutic delivery or tissue engineering. However, simple rules for either maximizing immunogenicity or abolishing it have yet to be elucidated, even though immunogenicity is a prime consideration for the design of any supramolecular biomaterial intended for use in vivo. Here we investigated a range of physicochemical properties of fibrillized peptide biomaterials, identifying negative surface charge as a means for completely abolishing antibody and $\mathrm{T}$ cell responses against them in mice, even when they display a competent epitope. The work was facilitated by the modularity of the materials, which enabled the generation of a set of co-assembled fibrillar peptide materials with broad ranges of surface properties. It was found that negative surface charge, provided via negatively charged amino acid residues, prevented $\mathrm{T}$ cell and antibody responses to antigencarrying assemblies because it prevented uptake of the materials by antigen presenting cells (APCs), which in turn prevented presentation of the epitope peptide in the APCs' major histocompatibility (MHC) class II molecules. Conversely, positive surface charge augmented the uptake of fibrillized peptides by APCs. These findings suggest that some surface characteristics such as extensive negative charge should be avoided in vaccine design using supramolecular peptide assemblies. More importantly, it provides a strategy to switch off potentially problematic immunogenicity for using these materials in non-immunological applications.
\end{abstract}

\section{Graphical abstract}

\footnotetext{
*Corresponding Author: Joel H. Collier, PhD, Associate Professor, Department of Biomedical Engineering, Duke University, Fitzpatrick CIEMAS 1393, Campus Box 90281, Durham, NC 27708-0281, T: 919-681-9768, joel.collier@duke.edu. None of the authors have financial conflicts of interest to disclose.

Supporting Information

Supporting Information is available free of charge via the Internet at http://pubs.acs.org. These materials include Table S1, a summary of synthesized peptides; and Figure S1, antibody isotype responses.
} 


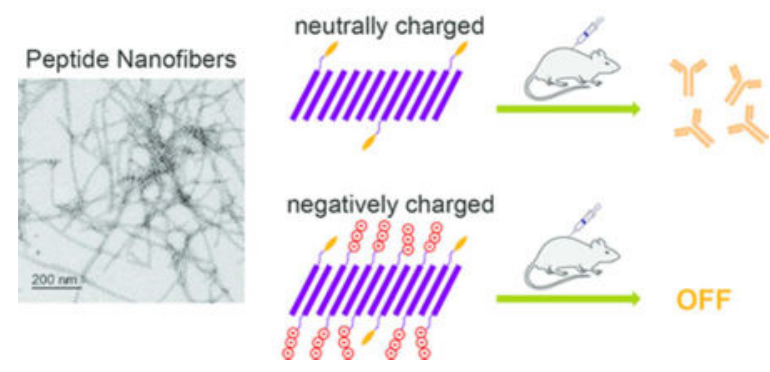

\section{Keywords}

nanofiber; supramolecular; immunogenicity; vaccine; biomaterial

Supramolecular or "self-assembling" nanomaterials have been increasingly investigated as platforms for immunological applications such as vaccines and immunotherapies. ${ }^{1-11}$ In parallel they have been investigated for many other traditionally non-immunological applications such as tissue engineering, cell scaffolds, wound repair, and drug delivery. ${ }^{12-22}$ In both contexts, it is of paramount importance to elicit appropriate immune responses, yet one set of applications demands maximal responses (vaccines, immunotherapies) while another demands attenuated responses (tissue engineering, drug delivery). Simple "switches" for adjusting immunogenicity in supramolecular nanomaterials would be extremely useful in both contexts, but at present the most reliable strategy is to either include strong $\mathrm{T}$ and $\mathrm{B}$ cell epitopes or avoid them altogether. ${ }^{2}$ Unfortunately such a strategy may not be tractable in many cases. For example, it may be challenging to avoid immunogenicity if a therapeutic peptide or protein nanomaterial incidentally contains one or more immunogenic epitopes and removal of the epitope ablates the therapeutic function. Therefore, in the present work we sought to develop simple methods for adjusting immunogenicity in supramolecular peptide nanomaterials.

We focused our work on fibrillizing peptides. Among supramolecular materials, fibrillar assemblies of peptides and peptide derivatives have received particular interest in a wide range of biomedical applications, both those that require immunogenicity ${ }^{2-4}$ and those that may need to avoid it. ${ }^{14,15}$ Our group has focused on the self-assembling peptide Q11 (QQKFQFQFEQQ), which assembles into nanofibers and hydrogels in physiological conditions. Epitope-bearing nanofibers can be formed by synthesizing Q11 peptides with various epitopes attached at their termini and allowing them to assemble, and these nanofibers are able to induce robust antigen-specific immune responses ${ }^{2-4}$ with minimal associated inflammation. ${ }^{3}$ Multiple peptides with different terminal epitopes can also coassemble into the same nanofiber with stoichiometric precision, ${ }^{23}$ which allows for the tuning of the epitope content within the nanofibers. By varying the ratio of $\mathrm{T}$ cell to $\mathrm{B}$ cell epitopes, for example, the potency and phenotype of immune responses can be adjusted. ${ }^{2}$ This modularity was exploited in the present work. Previously it has been determined that oligomerization and the presence of both B cell and $\mathrm{T}$ cell epitopes within the peptide sequence are prerequisites for immunogenicity in supramolecular peptide biomaterials. ${ }^{1,2,} 24$ However, if both these criteria are met, there is little current knowledge regarding how to otherwise tune the immunogenicity with precision. 
For other nanomaterials such as polymeric nanoparticles and liposomes, considerable previous work has investigated the extent to which size, shape, and surface chemistry influence tissue distribution, cellular uptake, clearance, and cytotoxicity, primarily in the context of drug delivery. ${ }^{25-29}$ Other studies have investigated how such properties affect nanoparticle uptake by immune cells ${ }^{30-32}$ and how they influence the overall immune response. ${ }^{33-39}$ For instance, the DeSimone group utilized the Particle Replication in NonWetting Templates (PRINT) process to prepare nanoparticles with either negatively or positively charged surfaces, holding other materials parameters constant. Following pulmonary immunizations, cationic but not anionic nanoparticles were able to stimulate germinal center B cell expansion, CD4 T cell activation, and both systemic and mucosal antibody responses. ${ }^{34}$ The Hubbell group reported that nanoparticle surface chemistry had a significant influence on immunogenicity because surface hydroxyl groups could activate complement. ${ }^{35}$ For fibrillar peptide self-assemblies, it is not known to what extent size, shape, hydrophobicity, and surface potential affect immunogenicity, yet these previous reports suggested that some amount of control over immunogenicity could be gained by adjusting these properties. Therefore, we sought to systematically compare the relative importance of each of these properties, exploiting the modular construction of selfassembled peptide nanofibers to do so. Peptides based on the Q11 self-assembling sequence have been shown previously to be capable of assembling into regular nanofibers even when appended with a wide range of $\mathrm{N}$-terminal functionalities, including variously charged, hydrophilic, and hydrophobic amino acid sequences, ${ }^{4,13,15,23,24}$ so we used this property in the present work to investigate a wide range of nanofiber properties. We found that among all of the modifications studied, negative surface potential had by far the most significant influence on immunogenicity, to the point where immune responses against epitopecontaining Q11 nanofibers could be switched off completely. This is an important and surprising finding because it provides a simple design rule for avoiding surface characteristics that may compromise immunogenicity for vaccines based on this system. Even more significantly, it suggests a strategy for cloaking peptide assemblies that contain immunologically problematic epitopes in a way that renders them non-immunogenic if an application demands it.

\section{RESULTS}

\section{Physiochemical characterization of supramolecular nanofibers}

To systematically compare the relative importance of positive surface charge, negative surface charge, hydrophobicity, and hydrophilicity, we generated a series of Q11-based peptides having a variety of different terminal functionalities (Table 1 ). Expected $\mathrm{m} / \mathrm{z}$ values were found by MALDI for each peptide (Table S1). N-terminal lysine or glutamic acid were employed for positive or negative terminal charges, respectively, while oligoethylene glycol (OEG) or propyl groups adjusted the relative hydrophilicity. We then created intermixed nanofibers containing both epitope-bearing peptides (OVAQ11, containing the OVA $323-339$ mixed B cell/T cell epitope peptide) and the variously functionalized peptides. We have previously demonstrated that several Q11 based peptides carrying different terminal functional sequences co-assemble into the same nanofiber, and we have developed preparation procedures for maximizing intermixing. ${ }^{23}$ In addition, two different peptides 
with N, N-dimethylated glutamine residues in the Q11 domain were also studied, where the dimethylated Gln residues were expected to disrupt $\beta$-sheet formation by disrupting side chain hydrogen bonding. ${ }^{40}$

We first characterized the fibrillization, conformation, and zeta potentials of nanofibers assembled from the N-terminally modified peptides alone and epitope-bearing nanofibers containing 10 mol\% OVAQ11, made by co-assembling the modified peptides and OVAQ11 at a 9:1 molar ratio. Positively charged KQ11 and KKKQ11 peptides formed long, uniform fibrils by Transmission Electron Microscopy (TEM) (Figure 1), with widths of 6-10 nm and lengths greater than $1000 \mathrm{~nm}$ (Table 2). They also formed similar fibrils when mixed with OVAQ11. By circular dichroism (CD), positively charged KQ11 and KKKQ11 exhibited $\beta$ sheet character, having broad minima between 216-224 nm and maxima near $205 \mathrm{~nm}$ (Figure 2a). Thioflavin T (ThT) binding was diminished compared to unmodified Q11 (Figure 2b), but mixing KQ11 and KKKQ11 9:1 with OVAQ11 restored ThT binding considerably (Figure 2c). The zeta potentials of KQ11 and KKKQ11 fibers were markedly positive, regardless of whether OVAQ11 was coassembled with it (Figure 3), with KKKQ11 conferring a greater zeta potential to the fibers than KQ11 as expected.

Negatively charged EQ11 and EEEQ11, like Q11 and the positively charged variants, formed long, uniform, and regular nanofibers by TEM (Figure 1), both by themselves and when mixed with OVAQ11. EEEQ11 by itself formed somewhat thinner fibers compared with EQ11 and Q11, with average widths around $5 \mathrm{~nm}$, but this effect was eliminated when EQ11 was mixed 9:1 with OVA-Q11 (Figure 1, far right panel). By CD, EQ11 was observed to have pronounced maxima and minima, in similar positions to Q11 and the positively charged variants (Figure 2a). Conversely, EEEQ11 had a weaker CD signal. This would have suggested that EEEQ11 had attenuated $\beta$-sheet character were it not for subsequent ThT binding measurements, which indicated significant $\beta$-sheet fibrillar structure for EQ11 and for EEEQ11, both of which had stronger ThT-binding signals than unmodified Q11 (Figure 2b). When mixed 9:1 with OVAQ11, the negatively charged variants continued to exhibit significant ThT binding, the EQ11 signal being greater than Q11's and the EEEQ11 signal being slightly less than Q11's (Figure 2c). Taken together, the TEM, CD, and ThT-binding data suggested that one $\mathrm{N}$-terminal Glu residue had negligible influence on the $\beta$-sheet fibrillar character of Q11, and three $\mathrm{N}$-terminal Glu residues still enabled strong $\beta$-sheet fibril formation, especially for epitope-bearing nanofibers. Meaningful attenuation of assembly was only observed for EEEQ11 by itself. Nanofibers containing N-terminal Glu residues had zeta potentials that were markedly negative (Figure 3), with EEEQ11 conferring slightly more negative charge than EQ11 when co-assembled with OVAQ11 (Figure $3 b$ ). Taken together with the characterization data for the positively charged variants, it was concluded that $\mathrm{N}$-terminally charged Q11 derivatives could be used to make drastic changes in the surface charge of epitope-bearing nanofibers, both positively and negatively, with negligible differences in fibrillar assembly.

Surprisingly, dimethylation of the side chains of the two central glutamines (Q11-2) or dimethylation of all of the glutamines (Q11-6) in the Q11 domain did not abolish fibrillization entirely, although nanofibers containing Q11-6 were slightly thinner than others (4.5 $\mathrm{nm}$ average width) and appeared to be more flexible, in that they had shorter persistence 
lengths by TEM (Figure 1, Table 2). CD indicated that both Q11-2 and Q11-6 were largely unstructured (Figure 2a), indicating a major disruption of $\beta$-sheet folding by dimethylation. Similarly, ThT signals were nearly abolished for both Q11-2 and Q11-6 (Figure 2b and c). With respect to surface charge, the zeta potential of Q11-2 was similarly neutral compared to Q11, and that of Q11-6 was slightly negative (Figure 3a). These trends remained when Q11-2 and Q11-6 were combined with OVAQ11 (Figure 3b). Collectively, dimethylation of the glutamines caused increasing disruption of fibrillization with minor influences on surface charge.

Adjustment of the hydrophilicity of Q11 had a smaller effect on the folding and surface properties of formed nanofibers. OEGQ11 and propylQ11 formed nanofibers indistinguishable from Q11 (Figure 1), and both were predominantly $\beta$-sheet by CD (Figure 2a). PropylQ11 bound ThT well, both by itself or when co-assembled with OVAQ11 (Figure $2 \mathrm{~b}$ and $\mathrm{c}$ ), while OEGQ11 showed diminished ThT binding (Figure $2 \mathrm{~b}$ and c). This diminished ThT binding was likely a result of the OEG groups obscuring the ThT binding sites, as both CD and TEM indicated strong $\beta$-sheet fibrillar character. Neither propyl groups nor OEG groups significantly altered the neutral zeta potential of Q11, and this was true for both individual peptides and those mixed with epitope-bearing OVAQ11 (Figure 3a and b).

In sum, the characterization of all of the N-terminally modified Q11 derivatives indicated that N-terminal Glu and Lys residues had a strong influence on nanofiber zeta potential with negligible or small influences on fibrillar structure, OEG and propyl modifications had a negligible impact on fiber assembly and zeta potential, and N, N-dimethylation of the Gln residues significantly disrupted fibrillar assembly but had a small impact on zeta potential.

\section{Surface potential-dependent antibody and $\mathrm{T}$ cell responses}

Mice were immunized with Q11 or modified peptides fibrillized with OVAQ11 at a 9:1 molar ratio. Consistent with our previous reports, ${ }^{3,4,41}$ unmodified Q11/OVAQ11 nanofibers induced OVA-specific antibody responses after one boost and served as a baseline for the study (Figure 4). Among the modified peptides, those bearing negatively charged Nterminal amino acids exerted the most dramatic effect, significantly diminishing antibody responses in the case of EQ11 and abolishing them entirely in the case of EEEQ11 (Figure 4). PropylQ11, Q11-2, and Q11-6 also led to diminished antibody responses, with Q11-6 showing the most dramatic reduction among the three (Figure 4). Nanofibers with Nterminal lysine residues (KQ11 or KKKQ11) or hydrophilic OEG were equivalently immunogenic compared to Q11. For these groups, no diminishment of antibody responses was observed.

The abolishment of antibody responses by EEEQ11 was complete. No mice in two independently studied groups of 4 raised even a detectable titer. Even for Q11-6, which had severely compromised $\beta$-sheet structure, one mouse raised a titer of 3 (Figure 4). In this way, the negative charge provided by EEEQ11 was an even stronger means for preventing antibody responses than broad disruption of the nanofiber, which itself was already known as a strategy to avoid antibody responses. ${ }^{24}$ Even one negative charge on the N-terminus of Q11, provided by one glutamate residue, was sufficient to significantly diminish antibody responses (Figure 4). Conversely, positively charged $\mathrm{N}$-terminal residues had no influence 
on the ability of Q11 nanofibers to raise antibody responses, a stark difference. Interestingly, across all formulations that were able to raise responses, antibody isotype profiles were similar, with IgG1 being the dominant isotype (Figure S1a). This result indicated that the various $\mathrm{N}$-terminal modifications did not drastically influence the phenotype of the immune response, at least with respect to antibody isotypes. It is noteworthy that the immunogenicity did not correlate strongly with $\beta$-sheet content measured by CD or ThT binding. EEEQ11 and EQ11 maintained high $\beta$-sheet propensity but failed to induce strong immune responses. For Q11-6 $\beta$-sheet content was diminished but it also had a slight negative charge, so it is possible that the significant diminishment of antibody responses was a result of both factors. In sum, the analysis of antibody responses revealed the surprisingly strong influence of negative charge on the immunogenicity of Q11-based nanofibers.

From this point in the study onward, we refined our investigation to Q11, KQ11, EEEQ11 and Q11-6. Q11 and KQ11 represented nanofibers with undiminished immunogenicity, while EEEQ11 and Q11-6 represented peptides with significant diminishment. These groups were studied with respect to CD4 $\mathrm{T}$ cell responses, lymphatic draining, and uptake and presentation by antigen presenting cells. We first investigated whether the results observed for antibody responses remained consistent for CD4 T cell responses, using ELISPOT analysis (Figure 5). After 12 weeks of the immunization regimen (see methods), mice were boosted one more time and draining lymph nodes (inguinal, axillary, and brachial) were collected. Cells from the lymph nodes were cultured and stimulated with $5 \mu \mathrm{M}$ OVA peptide, and cells secreting IFN- $\gamma$ or IL-4 were quantified. By this measure, Q11 and KQ11 groups had strong CD4 T cell responses, while EEEQ11 and Q11-6 groups failed to induce any significant $\mathrm{T}$ cell responses (Figure 5). These results were quite consistent with the antibody studies: Both EEEQ11 and Q11-6 were incapable of raising T cell responses. The Q11-6 group had one weakly responding mouse, but there was no detectable $\mathrm{T}$ cell response at all for EEEQ11 (Figure 5, inset).

\section{Efficient lymphatic draining of modified nanofibers}

Having found that nanofiber zeta potential contributes strongly to the overall immunogenicity, we tested the hypothesis that surface properties may influence lymphatic draining and trafficking of the nanofibers. Poor entry into lymph nodes could result in compromised immune responses, as lymphatic draining is critical for many nano-engineered immunotherapies. ${ }^{1,42-44}$ Peptide nanofibers containing modified peptides, $10 \mathrm{~mol} \%$ OVAQ11, and $1 \mathrm{~mol} \%$ fluorescent TAMRA-OVAQ11 were prepared to track the lymphatic draining using ex vivo imaging. Draining lymph nodes (brachial, axillary, and inguinal) were collected and imaged using an IVIS 200 imager $24 \mathrm{~h}$ after subcutaneous immunization. This time point was chosen to emphasize draining of the assemblies rather than slower trafficking of the materials by antigen-presenting cells. By this measure, all peptide nanofibers were drained to the lymph nodes (Figure 6). Interestingly, Q11-6 drained most efficiently, with considerably more accumulation in all lymph nodes tested than Q11. It is not clear why this was the case, but it is known that size is an important determinant of whether a particle can enter the lymphatic system and drain efficiently to lymph nodes, and that particles smaller than $200 \mathrm{~nm}$ drain with particular efficiency. ${ }^{44}$ It is not clear to what extent such metrics would apply to the high aspect ratio nanofibers studied here, but it is possible that Q11-6's 
increased lymph node drainage could have arisen from smaller size (widths of about $1 / 2$ that of other fibers, Table 2) and potential degradation into smaller particles. KQ11 and EEEQ11 trafficked similarly to each other (Figure 6), at a level slightly greater than Q11 (Figure 6). These findings indicated that surface charge did not significantly affect gross lymphatic draining, and that the diminished responses seen with the negatively charged assemblies could not be attributed to reduced entry into lymph nodes.

\section{Differential uptake and presentation efficiency by antigen presenting cells}

For the activation of antigen-specific $\mathrm{T}$ helper cells, antigens need to be internalized by antigen-presenting cells (APCs), proteolyzed (processed) into short T cell epitopes, loaded into class-II major histocompatibility molecules (MHC class II), and presented to T cells on the APC surface. Antigen-specific T cells, once activated, then go on to help B cells produce antibodies. Owing to the fact that both $\mathrm{T}$ cell responses and $\mathrm{B}$ cell responses were eliminated by negatively charged EEEQ11, we hypothesized that significant charge on the nanofibers may interfere with the process of antigen uptake, processing, and presentation. To test this hypothesis, we studied nanofiber internalization using fluorescent nanofibers and flow cytometry, followed by subsequent experiments with reporter cells (DOBW) that can detect appropriately processed and MHC class II-presented epitopes in cultures of APCs. TAMRAlabeled nanofibers were injected intraperitoneally, and cells in intraperitoneal lavage fluid were collected and stained for flow cytometry. Dendritic cells were gated as the F4/80negative/MHC class II-high CD11c+ population, while macrophages were gated as the F4/80-positive population. For the Q11 group, $18.1 \%$ of dendritic cells and 20.9\% of macrophages were found to be TAMRA-positive; that is, these cells had acquired peptide nanofibers (Figure 7). In stark contrast, for EEEQ11 and Q11-6, negligible uptake by macrophages or DCs was observed (Figure 7). For dendritic cells, this effect was especially pronounced (Figure $7 \mathrm{~b}$, inset). Interestingly, the uptake of positively charged KQ11 containing nanofibers was considerably greater than even Q11, to the point that around half of DCs and almost all macrophages took up KQ11 nanofibers (Figure 7b). To control the different doses of nanofibers received by APCs in vivo, the efficiency of cell internalization was further studied in vitro using cultured bone marrow dendritic cells (BMDCs). Exact doses of fluorescently labeled nanofibers with different surface charges were added to CpGstimulated BMDCs, and nanofiber uptake was evaluated by flow cytometry. Results from this in vitro experiment corresponded strikingly with observations from intraperitoneally delivered nanofibers (Figure 7c). In both cases, positive charge augmented nanofiber uptake by dendritic cells and macrophages, and negative charge abolished it. The vast majority of Flt-3L stimulated cells were dendritic cells (>97\%), but macrophages were a detectable component of these cultures (less than 3\%), so uptake by both populations is reported in Figure 7c. Overall these findings correspond with the previous findings of DeSimone and colleagues, who observed that positive charge enhanced nanoparticle uptake and subsequent immune responses for PRINT nanoparticles. ${ }^{33,34}$

Since the uptake study by flow cytometry could not differentiate whether fluorescently labeled cells had actually internalized the peptides rather than merely binding them on their surfaces, presentation efficiency was investigated further. DOBW cells are hybridomas that produce IL-2 when they encounter APCs presenting the OVA epitope in MHC class II 
(Figure 8a). Therefore, the concentration of IL-2 from the culture medium is an accurate indicator of presentation efficiency. Mice were intraperitoneally immunized with nanofibers containing OVAQ11 and the variously modified Q11 peptides, and cells from intraperitoneal lavage fluid were collected $18 \mathrm{~h}$ later and cultured ex vivo with DOBW cells for $20 \mathrm{~h}$. Concentrations of IL-2 in cell culture medium were quantified by ELISA. By themselves, without co-culturing with DOBW cells, cells from lavage fluid did not produce any IL-2 (Figure 8b). Coinciding with the flow cytometry results described above, Q11-based nanofibers were processed and presented, as reflected by significant IL-2 production by DOBW cells (Figure 8c). KQ11-based nanofibers showed an even higher presentation efficiency (Figure 8c), consistent with the uptake experiments. For EEEQ11 and Q11-6, neither was capable of being processed to stimulate DOBW T cells, as neither group produced any IL-2 above background (Figure 8c). That is, APCs failed to present OVA in their surface MHC class II when the antigen was supplied to the APCs in the form of nanofibers containing either EEEQ11 or Q11-6. These findings, along with the flow cytometry experiments described above (Figure 7), demonstrated that surface potential could be employed to diminish the ability of APCs to acquire and present nanofiber-associated antigens (in the case of negative charge) or to enhance nanofiber uptake (in the case of positive charge).

\section{Titrating surface potential in nanofiber vaccines}

Having established that the adjustment of surface charge could be used to eliminate the immunogenicity of self-assembled peptide nanofibers, we then investigated whether nanofibers could contain a lesser amount of charged peptides and still maintain their immunogenicity. $\mathrm{N}$-terminally modified peptides $(0.67 \mathrm{mM})$ were intermixed with OVAQ11 $(1.33 \mathrm{mM})$ at a $1: 2$ molar ratio. These nanofibers contained $33 \mathrm{~mol} \%$ modified peptide and 67 mol\% OVAQ11, considerably less modified peptide than the $90 \mathrm{~mol} \%$ present in the previously studied nanofibers reported above. The new nanofibers had similar morphology and dimensions (Figure 9a), and all had a slightly positive charge (Figure 9b). All peptide nanofibers also bound ThT, indicating significant $\beta$-sheet content (Figure 9c). In subcutaneous immunizations, all peptide nanofibers induced comparable OVA specific IgG titers (Figure 9d) over 12 weeks with similar IgG isotype profiles (Figure S1b). This study suggested that in order for negative surface potentials to diminish the immunogenicity of peptide nanofibers, a threshold amount of surface charge must be provided. In the absence of significant adjustments to nanofiber zeta potential, equivalent immune responses can be expected.

\section{Negative charges did not introduce immune tolerance}

To further elucidate how negative charges could modulate immune responses, our final experiment in this study investigated whether immune tolerance was introduced by negative charges. In one group, mice were immunized three times with negatively charged OVAcontaining nanofibers and then immunized with neutrally charged OVA-containing nanofibers, to determine if the negatively charged formulations induced some form of inhibitory effect. Strikingly, the neutrally charged material was rapidly immunogenic, even after multiple previous immunizations with negatively charged nanofibers, indicating that tolerance had not been brought about (Figure 10, Group 1). In a second group, mice were 
first immunized with neutrally charged OVA-containing nanofibers and then with negatively charged OVA-containing nanofibers. Again, no tolerizing effect was observed (Figure 10, Group 2). Hence, negatively charged nanofibers could neither prevent the immunogenicity of neutrally charged materials nor induce tolerance for established immune responses.

\section{DISCUSSION}

It is known that surface properties can significantly affect the fate and efficacy of nanomaterials in vivo and in vitro, ${ }^{25,26}$ and with respect to immunogenicity, nanomaterial properties have been adjusted previously to steer the immune response towards an antigenic payload. ${ }^{34,42,43}$ However, the extent to which these principles may apply to peptide assemblies or other supramolecular materials has remained to be elucidated, especially with regards to overall immune responses. The importance of the present work is that it illustrates a simple design rule, the use of negative charge, to limit the immunogenicity of selfassembled peptide nanofibers. This effect was surprisingly strong, as all measured immune responses against negatively charged peptide nanofibers were not merely attenuated, but abolished. In contrast, positively charged nanofibers were equivalently immunogenic compared to neutrally charged nanofibers, and their uptake by antigen presenting cells was enhanced considerably (results summarized in Table 3).

These findings raise important considerations for a wide range of applications. For example, peptide and protein self-assemblies are under considerable investigation for many nonimmunological applications such as tissue engineering and cell scaffolds, ${ }^{14}, 15,45 \mathrm{drug}$ delivery, ${ }^{16,20,2146-48}$ antimicrobials, ${ }^{49}$ wound healing, ${ }^{19,}, 50$ and others. ${ }^{51,52}$ In this broad range of applications, any antibody response against proteins, peptides, or other antigenic components incorporated into the materials could lead to blockage of the factors' function, early clearance of the material, or at worst, inflammatory rejection responses, although in general peptide assemblies have been found to be non-inflammatory to date. ${ }^{3} \mathrm{Co}$-assembling negatively charged peptides into supramolecular peptide materials intended for these purposes may represent a simple but powerful way of minimizing the occurrence of such sequelae. In the case of supramolecular assemblies intentionally designed to be immunogenic, such as those being investigated as vaccines and other immunotherapies by our laboratory ${ }^{2-5}$ and others, ${ }^{7-10}$ the present study suggests that significant negative charge could compromise immunogenicity and should be avoided. If, for example, a chosen epitope or antigen in a supramolecular vaccine formulation happens to carry a significant negative charge, it may be judicious to either counter the negative charge with other positively charged molecules in the nanomaterial or re-engineer the epitope.

In the present study we did not explore in mechanistic detail the specific reason why negatively charged peptide self-assemblies were not acquired, processed, and presented by antigen presenting cells, but one can speculate why this occurred. The simplest explanation would be that excess negative charge led to repulsion between the negatively charged surface of antigen-presenting cells and the self-assemblies. Positive charge on nanoparticles has been recently shown to enhance such processes. ${ }^{33,34}$ This notion is supported by the observation that no immune tolerizing effect was established by negative charges. Also, it should be noted that the antigen acquisition and activation studies were performed for 
intraperitoneal injections. It may be possible that nanofibers delivered to APCs in lymph nodes or via other routes may be differently acquired, but the abolishment of immune responses even for subcutaneous injections makes this unlikely.

Finally, a determination of whether this phenomenon applies to other nanomaterials would be an important future study. If nanoparticles, nanofibers, and other supramolecular nanomaterials can be rendered non-immunogenic even when they contain competent antigens, B cell epitopes, and T cell epitopes, it would be a boon for their use in biomedical applications where immunogenicity is counterproductive. As a specific example, selfassembled nanomaterials presenting targeting moieties such as proteins or antibodies would circulate for longer periods if immune responses against them were attenuated. This would be especially important for nanomaterials delivered repeatedly and thus at risk for developing immune responses against them over time. It would also be important to determine how strong the effect of negative charge is on the immunogenicity of other widely used synthetic vaccine platforms, including micelles, ${ }^{7,8}$ self-assembling polypeptide nanoparticles, ${ }^{10}$ polymer nanoparticles, ${ }^{35}$ and other particulate-based materials. The fact that similar charge effects have been observed by others, for example in polymer nanoparticles generated by PRINT processing, ${ }^{33,34}$ indicates that this principle may apply well beyond self-assembled peptides, but future systematic evaluation of each of these platforms would be necessary to confirm this.

\section{CONCLUSIONS}

We investigated the immunogenicity of antigen-bearing self-assembling peptides coassembled into nanofibers with other peptides bearing different charges, hydrophobic groups, or hydrophilic groups. We compared immune responses to these materials with those having significant attenuation of their assembly via $\mathrm{N}, \mathrm{N}$-dimethylation of their glutamine residues. Characterization studies revealed that charged residues placed $\mathrm{N}$-terminally to the Q11 self-assembling domain had a small or negligible impact on nanofiber formation, yet immune responses were significantly modulated. Negatively charged nanofibers were incapable of raising B cell/antibody responses or $\mathrm{T}$ cell responses, and they were unable to be acquired and presented by antigen presenting cells. Conversely, positively charged nanofibers maintained their ability to raise $\mathrm{T}$ cell and $\mathrm{B}$ cell responses, and were acquired avidly by antigen presenting cells. These findings illustrate a simple design rule for modulating the immunogenicity of self-assembled peptide biomaterials.

\section{METHODS}

\section{Peptide synthesis and formulation}

The peptides OVAQ11 (or OVA 323-339-SGSG-Q11, H2N-ISQAVHAAHAEINEAGRSGSG-QQKFQFQFEQQ-Am,), Q11 (Ac-QQKFQFQFEQQ-Am), KQ11 (Ac-K-SGSGQQKFQFQFEQQ-Am), KKKQ11 (Ac-KKK-SGSG-QQKFQFQFEQQ-Am), EQ11 (Ac-ESGSG-QQKFQFQFEQQ-Am), EEEQ11 (Ac-EEE-SGSG-QQKFQFQFEQQ-Am), OEGQ11 ( $\left.\mathrm{HO}\left(\mathrm{CH}_{2} \mathrm{CH}_{2} \mathrm{O}\right)_{2} \mathrm{CH}_{2} \mathrm{CH}_{2} \mathrm{CO}-Q Q K F Q F Q F E Q Q-A m\right)$, and PropylQ11 $\left(\mathrm{CH}_{3} \mathrm{CH}_{2} \mathrm{CH}_{2} \mathrm{CO}-\mathrm{SGSG}-\mathrm{QQKFQFQFEQQ}-\mathrm{Am}\right)$ were synthesized using standard Fmoc solid-phase synthesis as previously reported. ${ }^{15}$ To prepare the two peptides with $\mathrm{N}, \mathrm{N}$ - 
dimethylated Gln residues (Q*), Q11-2 (Ac-QQKFQ*FQ*FEQQ-Am) and Q11-6 (Ac$\mathrm{Q} * \mathrm{Q} * \mathrm{KFQ}{ }^{*} \mathrm{FQ} * \mathrm{FEQ} \mathrm{Q}^{*}$-Am), Fmoc-Glu(O-2-phenylisopropyl)-OH was used. Following standard Fmoc solid-phase synthesis, 2- phenylisopropyl groups were cleaved with 1\% TFA in dichloromethane (DCM) for 1-2 h. Peptides were then washed with dimethylformamide (DMF) and dried under vacuum. To perform amidation, $1 \mathrm{mmol}$ of benzotriazole-1-yl-oxytris(dimethylamino)phosphonium hexafluorophosphate (BOP) was dissolved in $5 \mathrm{~mL}$ DMF and mixed with $2 \mathrm{~mL}$ of $2 \mathrm{M}$ dimethylamine in methanol. ${ }^{40}$ This was applied to the resin and reacted overnight under nitrogen. The resin was then then washed with DMF again and dried under vacuum, after which peptides were cleaved as using a standard TFA cleavage cocktail. ${ }^{15}$ OVA-Q11 was N-terminally conjugated with 5-(and-6)carboxytetramethylrhodamine (TAMRA) using1-ethyl-3-(3dimethylaminopropyl)carbodiimide (EDC) coupling. All peptides were purified by reversephase HPLC, and lyophilized as previously reported. ${ }^{15}$ Peptide identity was confirmed using matrix-assisted laser desorption/ionization mass spectrometry (MALDI-MS) on a Bruker Ultraflextreme MALDI-TOF mass spectrometer using a-cyano-4-hydroxycinnamic acid as the matrix.

To prepare immunization formulations, lyophilized peptides were weighed and intermixed by vortexing in a closed tube for $30 \mathrm{~min}$. Sterile ultrapure water was added to prepare $8 \mathrm{mM}$ solutions. After overnight incubation at $4{ }^{\circ} \mathrm{C}$, peptide solutions were diluted to $2 \mathrm{mM}$ in $1 \times$ PBS using sterile water and sterile 10× PBS (Fisher BP399-500) and incubated at room temperature for $3 \mathrm{~h}$. These preparations were used for immunizations. For quality control, endotoxin measurements were conducted on the same peptide solutions that were used for immunizations, using the Limulus Amebocyte Lysate chromogenic endpoint assay (Lonza). Endotoxin levels of all immunization preparations were $<0.5 \mathrm{EU} / \mathrm{mL}(<0.05 \mathrm{EU}$ per $100 \mu \mathrm{L}$ dose).

\section{Electron Microscopy}

Peptide nanofibers prepared at $2 \mathrm{mM}$ were diluted to $0.2 \mathrm{mM}$ with $1 \times \mathrm{PBS}$ and vigorously vortexed, then $5 \mu \mathrm{L}$ of diluted peptide nanofibers were deposited onto Formvar/Carbon coated 400 mesh copper grids (Electron Microscopy Sciences). The sample was allowed to incubate for 1 minute, then washed 5 times with $0.2 \mu \mathrm{m}$ filtered ultrapure water. Negative staining was performed for 1 minute with $1 \% \mathrm{w} / \mathrm{v}$ uranyl acetate in water. Staining solution was withdrawn with filter paper. Samples were imaged on a FEI Tecnai G2 Spirit TEM. Widths were measured in ImageJ. Measurements were made for the bright central portion of the nanofibers, and reported widths exclude the dark edges stained by uranyl acetate.

\section{Secondary structure analysis by Circular Dichroism (CD) and Thioflavin T (ThT) binding}

Prepared aqueous solutions of $2 \mathrm{mM}$ peptide were diluted to $0.2 \mathrm{mM}$ with $1 \times \mathrm{PBS}$ and vigorously vortexed. Far UV CD spectra were collected on a Jasco J-1500 CD spectrometer from $260 \mathrm{~nm}$ to $180 \mathrm{~nm}$ in a $0.1 \mathrm{~cm}$ path length cuvette. Five accumulations were averaged for each measurement with a wavelength increment of $1 \mathrm{~nm}$ and scanning speed of $100 \mathrm{~nm}$ per minute. For ThT binging assay, $20 \mu \mathrm{L}$ of prepared $2 \mathrm{mM}$ peptide nanofibers was added to $80 \mu \mathrm{L} 0.0025 \mathrm{mM}$ ThT in PBS in a 96 well plate. Fluorescence emission was scanned from $400-600 \mathrm{~nm}$ at a fixed excitation of $442 \mathrm{~nm}$ on a Tecan Infinite 200 Pro. 


\section{Zeta potential measurements}

Prepared $2 \mathrm{mM}$ aqueous peptides were diluted to $0.2 \mathrm{mM}$ with $1 \times$ PBS and vigorously vortexed. Zeta potential was measured with a Starna DTS1070 folded capillary cell on a Malvern Nano Zeta Sizer. Samples were allowed to equilibrate at $25^{\circ} \mathrm{C}$ for $3 \mathrm{~min}$, and triplicate measurements were averaged.

\section{Mice and immunizations}

Female C57BL/6 mice were purchased from Harlan Sprague Dawley and housed in a centralized animal facility at the University of Chicago. All procedures were approved by the University of Chicago Institutional Animal Care and Use Committee and were in compliance with the NIH Guide for the Care and Use of Laboratory Animals. Mice were anesthetized and the preparations described above were delivered subcutaneously (50 $\mu \mathrm{L}$ in two locations on the left and right flank). This amounts to a $20 \mathrm{nmol}$ ( $35 \mu \mathrm{g}$ ) dose of OVA $_{323-339}$ epitope peptide. Booster immunizations were given after 4 weeks at the same dose of the primary immunizations. Subcutaneous injections were used to study antibody responses, T cell responses, and lymphatic draining. Intraperitoneal injections were performed to study uptake by antigen presenting cells and presentation efficiencies. These constituted two $50 \mu \mathrm{L}$ intraperitoneal injections in the left and right side of the abdomen.

\section{Measurements of antibody and $\mathrm{T}$ cell responses}

Serum collected biweekly via the submandibular vein was analyzed for antigen-specific $\operatorname{IgG}$ by ELISA. Plates were first coated with $2 \mu \mathrm{g} / \mathrm{mL}$ streptavidin solution overnight at $4{ }^{\circ} \mathrm{C}$, washed with $0.05 \%$ (w/v) tween-20 in PBS (1× PBST), blocked by Superblock blocking buffer solution (Thermo Fisher, Cat\#37515), washed again, and then coated with $20 \mu \mathrm{g} / \mathrm{mL}$ of biotinylated peptide $\mathrm{OVA}_{323-339}$ (Biotin-pOVA) for $1 \mathrm{~h}$ at room temperature. Serially diluted sera in $1 \%(\mathrm{w} / \mathrm{v}) \mathrm{BSA}$ in $1 \times$ PBST were added to the plate, and OVA-specific $\operatorname{IgG}$ was detected by horseradish peroxidase conjugated $\mathrm{Fc} \gamma$ fragment specific goat anti-mouse IgG (Jackson Immuno Research, Cat \#115-035-071).

To analyze $\mathrm{T}$ cell activation by ELISPOT, mice were euthanized 7 days after the final booster immunization. Draining lymph nodes (inguinal, brachial, and axillary) were collected, and single-cell suspensions were prepared as previously reported. ${ }^{2,}{ }^{41}$ Briefly, 96well ELISPOT plates (Millipore, Cat\#MSIPS4510) were washed and coated overnight at $4{ }^{\circ} \mathrm{C}$ with anti-IFN- $\gamma$ (BD, Cat\#51-2525KZ) or anti-IL-4 (BD, Cat\#51-1819KZ) capture antibody. After blocking with complete RPMI medium for $2 \mathrm{~h}$ at $37^{\circ} \mathrm{C}, 200 \mu \mathrm{L}$ of $2.5 \mathrm{M} / \mathrm{mL}$ cells were seeded and stimulated with $5 \mu \mathrm{M}$ pOVA for $48 \mathrm{~h}$ in a $\mathrm{CO}_{2}$ incubator at $37^{\circ} \mathrm{C}$. Plates were then washed and incubated with biotinylated anti-IFN- $\gamma$ (BD, Cat\#51-1818KA) or anti-IL-4 (BD, Cat\#51-1804KZ) detection antibodies, then with streptavidin-alkaline phosphatase (Mabtech, Cat\#3310-10), and finally with the substrate Sigmafast BCIP/NBT (Sigma, Cat\#B5655). Plates were allowed to dry overnight before the spots were imaged and counted using an ELISPOT reader (Cellular Technology Ltd).

\section{Lymph node draining}

Mice were immunized with fluorescent nanofibers containing 1 mol\% TAMRA-OVAQ11. Draining lymph nodes were collected $24 \mathrm{~h}$ later and imaged using a Xenogen IVIS 200 
imaging system ( $535 \mathrm{~nm}$ excitation, $600 \mathrm{~nm}$ emission). Images were processed and quantified by the IVIS 200 software.

\section{Cell uptake and presentation}

Mice were euthanized $18 \mathrm{~h}$ after intraperitoneal (IP) immunization of fluorescently labeled nanofibers containing 1 mol\% TAMRA-OVAQ11. IP lavage was conducted using an intraperitoneal injection of $2 \mathrm{~mL}$ Hank's balanced salt solution (HBSS). The abdomen was massaged 40 times and about $1.2-1.5 \mathrm{~mL}$ of lavage fluid was withdrawn from the IP space. Cells were collected by centrifugation and washed once by flow buffer (PBS containing 2\% fetal bovine serum). After blocking the Fc receptor with 2.4G2 antibody (BD Bioscience, Cat\#: 553142), cells were stained for F4/80 (Biolegend, Cat\#: 123128), MHC class II (Biolegend, Cat\#: 107606), and CD11c (Biolegend, Cat\#: 117318). Cells were washed and resuspended in flow buffer with $1 \mu \mathrm{g} / \mathrm{mL}$ DAPI. Flow cytometry was performed on a BD LSRII and analyzed using FlowJo software. Macrophages were gated as F4/80-positive and dendritic cells (DC) were gated as F4/80-negative/ MHC class II-high/ CD11c-positive. The percentage of TAMRA-positive cells (having internalized labeled nanofibers) was calculated for both macrophage and DC populations.

To control the doses of nanofibers exposed to APCs, cellular uptake was also studied in vitro using bone marrow derived dendritic cells (BMDCs). Bone (femur and tibia) marrow cells were cultured in complete RPMI medium containing $200 \mathrm{ng} / \mu \mathrm{L}$ Flt-3L. Loosely bound cells and floating cells were collected on day 8 for assays. Fluorescently labeled peptide nanofibers $(1.8 \mathrm{mM}$ peptide + $0.2 \mathrm{mM}$ OVAQ11 + $0.02 \mathrm{mM}$ TAMRA-OVAQ11) were diluted to $0.2 \mathrm{mM}$ in complete RPMI medium containing $200 \mathrm{ng} / \mathrm{mL} \mathrm{CpG} \mathrm{(ODN} \mathrm{1826).} 250$ $\mu \mathrm{L}$ of these diluted peptide nanofibers were added to $250 \mu \mathrm{L}$ of cell suspension $\left(1 \times 10^{6}\right.$ cells $/ \mathrm{mL}$ final cell concentration) and cultured for $18 \mathrm{~h}$. Cells were stained for F4/80, CD11c, and MHCII for flow cytometry, as in in vivo studies. Again, DCs were gated as F4/80-negative/MHC class II-high/CD11c-positive. Less than 3\% of cells exhibited a macrophage phenotype (F4/80-positive), and the uptake efficiency in the macrophage population was also quantified.

To investigate presentation efficiency, cells from lavage fluid were washed, resuspended at $0.5 \mathrm{M} / \mathrm{mL}$ in complete RPMI medium, and seeded into 96 well plates (100 $\mu \mathrm{L}$ per well). Next DOBW reporter T cell hybridomas were added $(100 \mu \mathrm{L}$ of $0.5 \mathrm{M} / \mathrm{mL}$ cells in complete DMEM). DOBW cells produce IL-2 when they encounter their specific epitope $\left(\mathrm{OVA}_{323-339)}\right.$ complexed within the appropriate $\mathrm{MHC}$ class II (I-A $\left.{ }^{\mathrm{b}}\right)$. Co-cultures were incubated overnight in a $\mathrm{CO}_{2}$ incubator at $37{ }^{\circ} \mathrm{C}$. Cell culture medium was collected after a brief centrifugation ( $1500 \mathrm{rpm}$ for $5 \mathrm{~min}$ ), and the concentration of IL-2 in the media was measured by ELISA (BD, Cat\#55148).

\section{Statistical analysis}

Statistical analysis was performed in Graphpad Prism using 1 way or 2 way ANOVA with Dunnett's multiple comparison test as indicated in figure legends. Means \pm standard deviations are presented unless otherwise noted. 


\section{Supplementary Material}

Refer to Web version on PubMed Central for supplementary material.

\section{Acknowledgments}

We would like to thank T. Sun for assistance with blood draws, Y. Wu for assistance with dimethylation of glutamine, C. Harding for providing the DOBW cells, and A. Chong for helpful discussions. The work described in this article was conducted at the University of Chicago and supported by the National Institutes of Health (NIBIB, 1R01EB009701; NIAID 1R01AI118182). Its contents are solely the responsibility of the authors and do not necessarily represent the official views of these agencies.

\section{References}

1. Wen Y, Collier JH. Supramolecular Peptide Vaccines: Tuning Adaptive Immunity. Curr. Opin. Immunol. 2015; 35:73-79. [PubMed: 26163376]

2. Pompano RR, Chen J, Verbus EA, Han H, Fridman A, McNeely T, Collier JH, Chong AS. Titrating T-cell Epitopes Within Self-Assembled Vaccines Optimizes CD4+ Helper T Cell and Antibody Outputs. Adv. Healthcare Mater. 2014; 3:1898-1908.

3. Chen J, Pompano RR, Santiago FW, Maillat L, Sciammas R, Sun T, Han H, Topham DJ, Chong AS, Collier JH. The Use of Self-Adjuvanting Nanofiber Vaccines to Elicit High-Affinity B Cell Responses to Peptide Antigens Without Inflammation. Biomaterials. 2013; 34:8776-8785. [PubMed: 23953841]

4. Rudra JS, Tian YF, Jung JP, Collier JH. A Self-Assembling Peptide Acting as an Immune Adjuvant. Proc. Natl. Acad. Sci. U. S. A. 2009; 107:622-627. [PubMed: 20080728]

5. Hudalla GA, Sun T, Gasiorowski JZ, Han H, Tian YF, Chong AS, Collier JH. Gradated Assembly of Multiple Proteins Into Supramolecular Nanomaterials. Nat. Mater. 2014; 13:829-836. [PubMed: 24930032]

6. Huang Z-H, Shi L, Ma J-W, Sun Z-Y, Cai H, Chen Y-X, Zhao Y-F, Li Y-M. a Totally Synthetic, Self-Assembling, Adjuvant-Free MUC1 Glycopeptide Vaccine for Cancer Therapy. J. Am. Chem. Soc. 2012; 134:8730-8733. [PubMed: 22587010]

7. Trent A, Ulery BD, Black MJ, Barrett JC, Liang S, Kostenko Y, David NA, Tirrell MV. Peptide Amphiphile Micelles Self-Adjuvant Group A Streptococcal Vaccination. AAPS J. 2015; 17:380388. [PubMed: 25527256]

8. Black M, Trent A, Kostenko Y, Lee JS, Olive C, Tirrell M. Self-Assembled Peptide Amphiphile Micelles Containing a Cytotoxic T-Cell Epitope Promote a Protective Immune Response In Vivo. Adv. Mater. (Weinheim Ger.). 2012; 24:3845-3849.

9. Rudra JS, Mishra S, Chong AS, Mitchell RA, Nardin EH, Nussenzweig V, Collier JH. SelfAssembled Peptide Nanofibers Raising a Durable Antibody Response Against a Malaria Epitope. Biomaterials. 2012; 33:6476-6484. [PubMed: 22695068]

10. El Bissati K, Zhou Y, Dasgupta D, Cobb D, Dubey JP, Burkhard P, Lanar DE, McLeod R. Effectiveness of a Novel Immunogenic Nanoparticle Platform for Toxoplasma Peptide Vaccine in HLA Transgenic Mice. Vaccine. 2014; 32:3243-3248. [PubMed: 24736000]

11. Wen Y, Liu W, Bagia C, Zhang S, Bai M, Janjic JM, Giannoukakis N, Gawalt ES, Meng WS. Antibody-Functionalized Peptidic Membranes for Neutralization of Allogeneic Skin AntigenPresenting Cells. Acta Biomater. 2014; 10:4759-4767. [PubMed: 25117952]

12. Boekhoven J, Stupp SI. 25th Anniversary Article: Supramolecular Materials for Regenerative Medicine. Adv. Mater. (Weinheim Ger.). 2014; 26:1642-1659.

13. Collier JH, Rudra JS, Gasiorowski JZ, Jung JP. Multi-Component Extracellular Matrices Based on Peptide Self-Assembly. Chem. Soc. Rev. 2010; 39:3413-3424. [PubMed: 20603663]

14. Holmes TC, de Lacalle S, Su X, Liu G, Rich A, Zhang S. Extensive Neurite Outgrowth and Active Synapse Formation on Self-Assembling Peptide Scaffolds. Proc. Natl. Acad. Sci. U. S. A. 2000; 97:6728-6733. [PubMed: 10841570] 
15. Jung JP, Nagaraj AK, Fox EK, Rudra JS, Devgun JM, Collier JH. Co-Assembling Peptides as Defined Matrices for Endothelial Cells. Biomaterials. 2009; 30:2400-2410. [PubMed: 19203790]

16. Kumar VA, Taylor NL, Shi S, Wickremasinghe NC, D'Souza RN, Hartgerink JD. Self-Assembling Multidomain Peptides Tailor Biological Responses Through Biphasic Release. Biomaterials. 2015; 52:71-78. [PubMed: 25818414]

17. Morgan CE, Dombrowski AW, Rubert Perez CM, Bahnson ESM, Tsihlis ND, Jiang W, Jiang Q, Vercammen JM, Prakash VS, Pritts TA, Stupp SI, Kibbe MR. Tissue-Factor Targeted Peptide Amphiphile Nanofibers as an Injectable Therapy To Control Hemorrhage. ACS Nano. 2016; 10:899-909. [PubMed: 26700464]

18. Tian YF, Hudalla GA, Han H, Collier JH. Controllably Degradable $\beta$-sheet Nanofibers and Gels from Self-Assembling Depsipeptides. Biomater. Sci. 2013; 1:1037-1045.

19. Schneider A, Garlick JA, Egles C. Self-Assembling Peptide Nanofiber Scaffolds Accelerate Wound Healing. PLoS ONE. 2008; 3:e1410. [PubMed: 18183291]

20. Koutsopoulos S, Unsworth LD, Nagai Y, Zhang S. Controlled Release of Functional Proteins Through Designer Self-Assembling Peptide Nanofiber Hydrogel Scaffold. Proc. Natl. Acad. Sci. U. S. A. 2009; 106:4623-4628. [PubMed: 19273853]

21. Kumar VA, Shi S, Wang BK, Li IC, Jalan AA, Sarkar B, Wickremasinghe NC, Hartgerink JD. Drug-Triggered and Cross-Linked Self-Assembling Nanofibrous Hydrogels. J. Am. Chem. Soc. 2015; 137:4823-4830. [PubMed: 25831137]

22. Wen Y, Kolonich HR, Kruszewski KM, Giannoukakis N, Gawalt ES, Meng WS. Retaining Antibodies in Tumors with a Self-Assembling Injectable System. Mol. Pharmaceutics. 2013; 10:1035-1044.

23. Gasiorowski JZ, Collier JH. Directed Intermixing in Multicomponent Self-Assembling Biomaterials. Biomacromolecules. 2011; 12:3549-3558. [PubMed: 21863894]

24. Rudra JS, Sun T, Bird KC, Daniels MD, Gasiorowski JZ, Chong AS, Collier JH. Modulating Adaptive Immune Responses to Peptide Self-Assemblies. ACS Nano. 2012; 6:1557-64. [PubMed: 22273009]

25. Petros RA, DeSimone JM. Strategies in the Design of Nanoparticles for Therapeutic Applications. Nat. Rev. Drug Discovery. 2010; 9:615-627. [PubMed: 20616808]

26. Davis ME, Chen Z, Shin DM. Nanoparticle Therapeutics: An Emerging Treatment Modality for Cancer. Nat. Rev. Drug Discovery. 2008; 7:771-782. [PubMed: 18758474]

27. Frohlich E. The Role of Surface Charge in Cellular Uptake and Cytotoxicity of Medical Nanoparticles. Int. J. Nanomed. 2012; 7:5577-5591.

28. He C, Hu Y, Yin L, Tang C, Yin C. Effects of Particle Size and Surface Charge on Cellular Uptake and Biodistribution of Polymeric Nanoparticles. Biomaterials. 2010; 31:3657-3666. [PubMed: 20138662]

29. Campbell RB, Fukumura D, Brown EB, Mazzola LM, Izumi Y, Jain RK, Torchilin VP, Munn LL. Cationic Charge Determines the Distribution of Liposomes Between the Vascular and Extravascular Compartments of Tumors. Cancer Res. 2002; 62:6831-6836. [PubMed: 12460895]

30. Fytianos K, Rodriguez-Lorenzo L, Clift MJD, Blank F, Vanhecke D, von Garnier C, Petri-Fink A, Rothen-Rutishauser B. Uptake Efficiency of Surface Modified Gold Nanoparticles Does Not Correlate with Functional Changes and Cytokine Secretion in Human Dendritic Cells In Vitro. Nanomedicine (N. Y., NY, U. S.). 2015; 11:633-644.

31. Ma Y, Zhuang Y, Xie X, Wang C, Wang F, Zhou D, Zeng J, Cai L. The Role of Surface Charge Density in Cationic Liposome-Promoted Dendritic Cell Maturation and Vaccine-Induced Immune Responses. Nanoscale. 2011; 3:2307-2314. [PubMed: 21499635]

32. Foged C, Brodin B, Frokjaer S, Sundblad A. Particle Size and Surface Charge Affect Particle Uptake by Human Dendritic Cells in an In Vitro Model. Int. J. Pharm. (Amsterdam, Neth.). 2005; 298:315-322.

33. Fromen CA, Rahhal TB, Robbins GR, Kai MP, Shen TW, Luft JC, DeSimone JM. Nanoparticle Surface Charge Impacts Distribution, Uptake and Lymph Node Trafficking by Pulmonary AntigenPresenting Cells. Nanomedicine (N. Y., NY, U. S.). 2016; 12:677-687. 
34. Fromen CA, Robbins GR, Shen TW, Kai MP, Ting JP, DeSimone JM. Controlled Analysis of Nanoparticle Charge on Mucosal and Systemic Antibody Responses Following Pulmonary Immunization. Proc. Natl. Acad. Sci. U. S. A. 2015; 112:488-493. [PubMed: 25548169]

35. Reddy ST, van der Vlies AJ, Simeoni E, Angeli V, Randolph GJ, O'Neil CP, Lee LK, Swartz MA, Hubbell JA. Exploiting Lymphatic Transport and Complement Activation in Nanoparticle Vaccines. Nat. Biotechnol. 2007; 25:1159-1164. [PubMed: 17873867]

36. Kumar S, Anselmo AC, Banerjee A, Zakrewsky M, Mitragotri S. Shape and Size-Dependent Immune Response to Antigen-Carrying Nanoparticles. J. Controlled Release. 2015; 220(Part A): 141-148.

37. Bennewitz NL, Babensee JE. The Effect of the Physical Form of Poly(Lactic-co-Glycolic Acid) Carriers on the Humoral Immune Response to Co-Delivered Antigen. Biomaterials. 2005; 26:2991-2999. [PubMed: 15603794]

38. Henriksen-Lacey M, Christensen D, Bramwell VW, Lindenstrom T, Agger EM, Andersen P, Perrie Y. Liposomal Cationic Charge and Antigen Adsorption are Important Properties for the Efficient Deposition of Antigen at the Injection Site and Ability of the Vaccine to Induce a CMI Response. J. Controlled Release. 2010; 145:102-108.

39. Thomas C, Gupta V, Ahsan F. Influence of Surface Charge of PLGA Particles of Recombinant Hepatitis B Surface Antigen in Enhancing Systemic and Mucosal Immune Responses. Int. J. Pharm. (Amsterdam, Neth.). 2009; 379:41-50.

40. Lanning JD, Hawk AJ, Derryberry J, Meredith SC. Chaperone-like N-Methyl Peptide Inhibitors of Polyglutamine Aggregation. Biochemistry. 2010; 49:7108-7118. [PubMed: 20583779]

41. Sun T, Han H, Hudalla GA, Wen Y, Pompano RR, Collier JH. Thermal Stability of Self-Assembled Peptide Vaccine Materials. Acta Biomater. 2016; 30:62-71. [PubMed: 26584836]

42. Irvine DJ, Swartz MA, Szeto GL. Engineering synthetic vaccines using cues from natural immunity. Nat. Mater. 2013; 12:978-990. [PubMed: 24150416]

43. Irvine DJ, Hanson MC, Rakhra K, Tokatlian T. Synthetic Nanoparticles for Vaccines and Immunotherapy. Chem. Rev. (Washington, DC, U. S.). 2015; 115:11109-11146.

44. Bachmann MF, Jennings GT. Vaccine Delivery: A Matter of Size, Geometry, Kinetics and Molecular Patterns. Nat. Rev. Immunol. 2010; 10:787-796. [PubMed: 20948547]

45. Lindsey S, Piatt JH, Worthington P, Sonmez C, Satheye S, Schneider JP, Pochan DJ, Langhans SA. Beta Hairpin Peptide Hydrogels as an Injectable Solid Vehicle for Neurotrophic Growth Factor Delivery. Biomacromolecules. 2015; 16:2672-2683. [PubMed: 26225909]

46. Li J, Li X, Kuang Y, Gao Y, Du X, Shi J, Xu B. Self-Delivery Multifunctional Anti-HIV Hydrogels for Sustained Release. Adv. Healthcare Mater. 2013; 2:1586-1590.

47. Kalafatovic D, Nobis M, Javid N, Frederix PWJM, Anderson KI, Saunders BR, Ulijn RV. MMP-9 Triggered Micelle-to-Fibre Transitions for Slow Release of Doxorubicin. Biomater. Sci. 2015; 3:246-249. [PubMed: 26218115]

48. Liu W, Saunders MJ, Bagia C, Freeman EC, Fan Y, Gawalt ES, Waggoner AS, Meng WS. Local Retention of Antibodies In Vivo With An Injectable Film Embedded With A Fluorogen-Activating Protein. J. Controlled Release. 2016; 230:1-12.

49. Veiga AS, Sinthuvanich C, Gaspar D, Franquelim HG, Castanho MA, Schneider JP. Arginine-Rich Self-Assembling Peptides as Potent Antibacterial Gels. Biomaterials. 2012; 33:8907-8916. [PubMed: 22995710]

50. Vigneswaran Y, Han Y, De Loera R, Wen Y, Zhang X, Sun T, Mora-Solano C, Collier JH. Peptide Biomaterials Raising Adaptive Immune Responses in Wound Healing Contexts. J. Biomed. Mater. Res., Part A. 2016

51. Zhou J, Du X, Yamagata N, Xu B. Enzyme-Instructed Self-Assembly of Small d-Peptides as a Multiple-Step Process for Selectively Killing Cancer Cells. J. Am. Chem. Soc. 2016; 138:38133823. [PubMed: 26966844]

52. Kuang Y, Du X, Zhou J, Xu B. Supramolecular Nanofibrils Inhibit Cancer Progression In Vitro and In Vivo. Adv. Healthcare Mater. 2014; 3:1217-1221. 

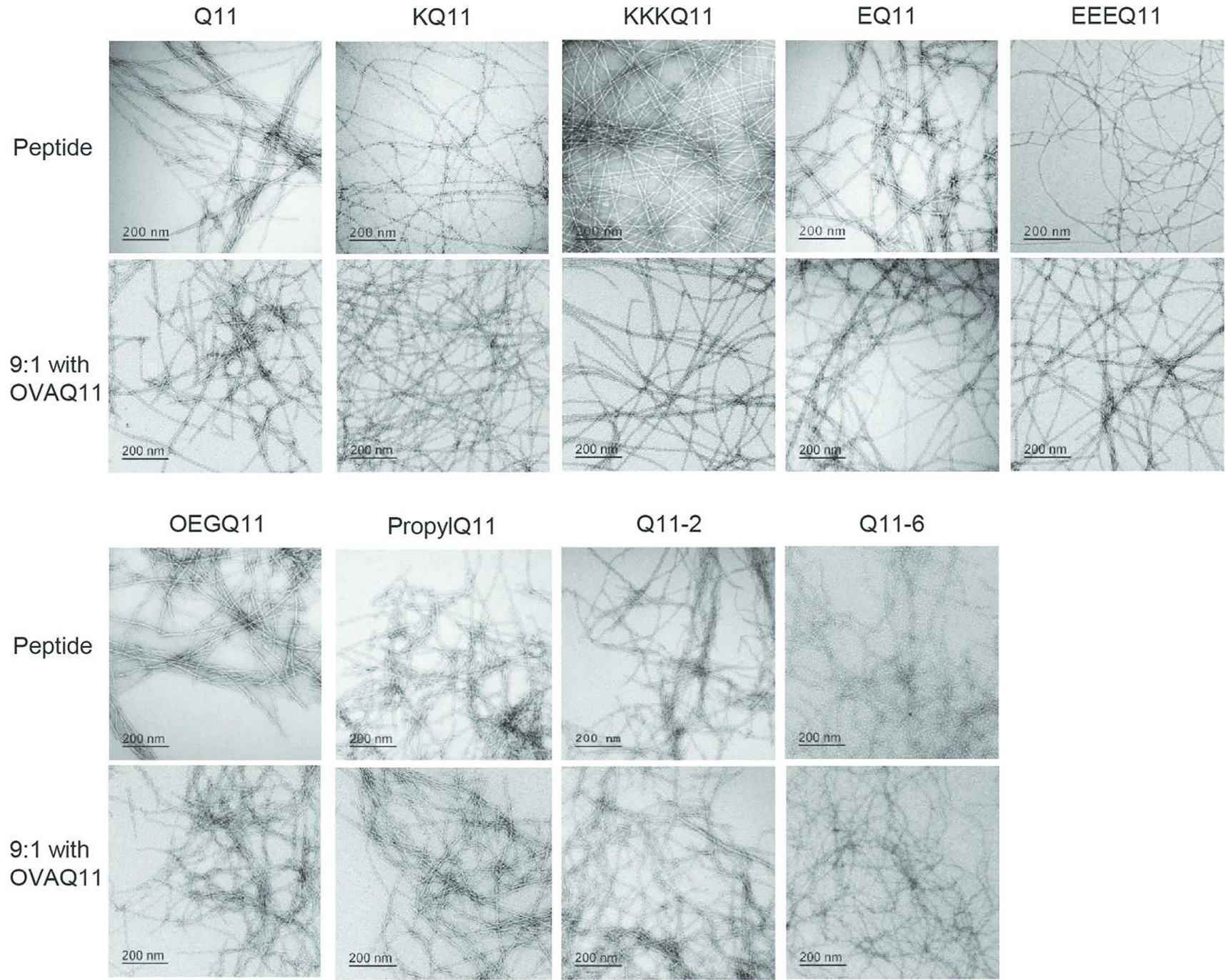

Figure 1. Negative stained TEM images of self-assembled nanofibers

Nanofibers assembled from $2 \mathrm{mM}$ total peptide were diluted to $0.2 \mathrm{mM}$ for spotting onto

TEM grids (scale bar: $200 \mathrm{~nm}$ ). Shown are nanofibers from each type of peptide alone (top panel for each type), plus those containing $90 \mathrm{~mol} \%$ modified peptide and $10 \mathrm{~mol} \%$ OVAQ11 (bottom panel for each type, produced by mixing $1.8 \mathrm{mM}$ modified peptide with 0.2 mM OVAQ11, a 9:1 ratio). 
a

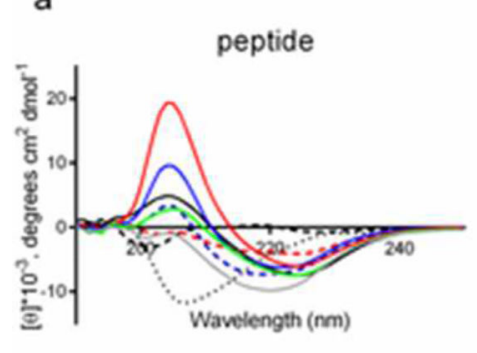

b

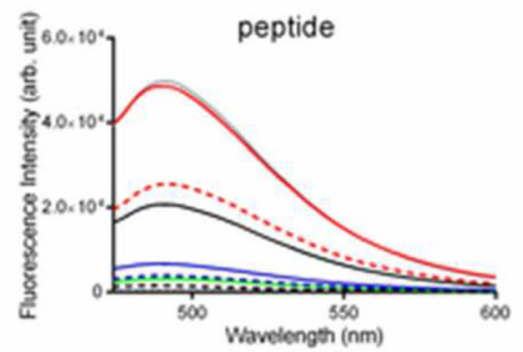

c

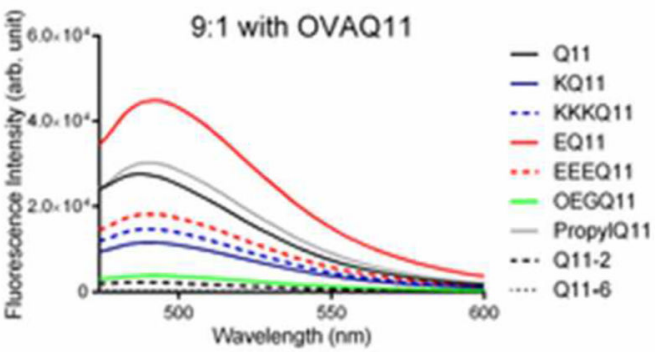

Figure 2. Secondary structure characterization of modified peptides CD spectra (a) and ThT fluorescence spectra (b) of individual modified peptides ( $a, b)$ and modified peptides mixed 9:1 with OVAQ11 (c). N, N-dimethylation of glutamine side chains particularly disrupted $\beta$-sheet structure $(\mathrm{a}-\mathrm{c})$. 

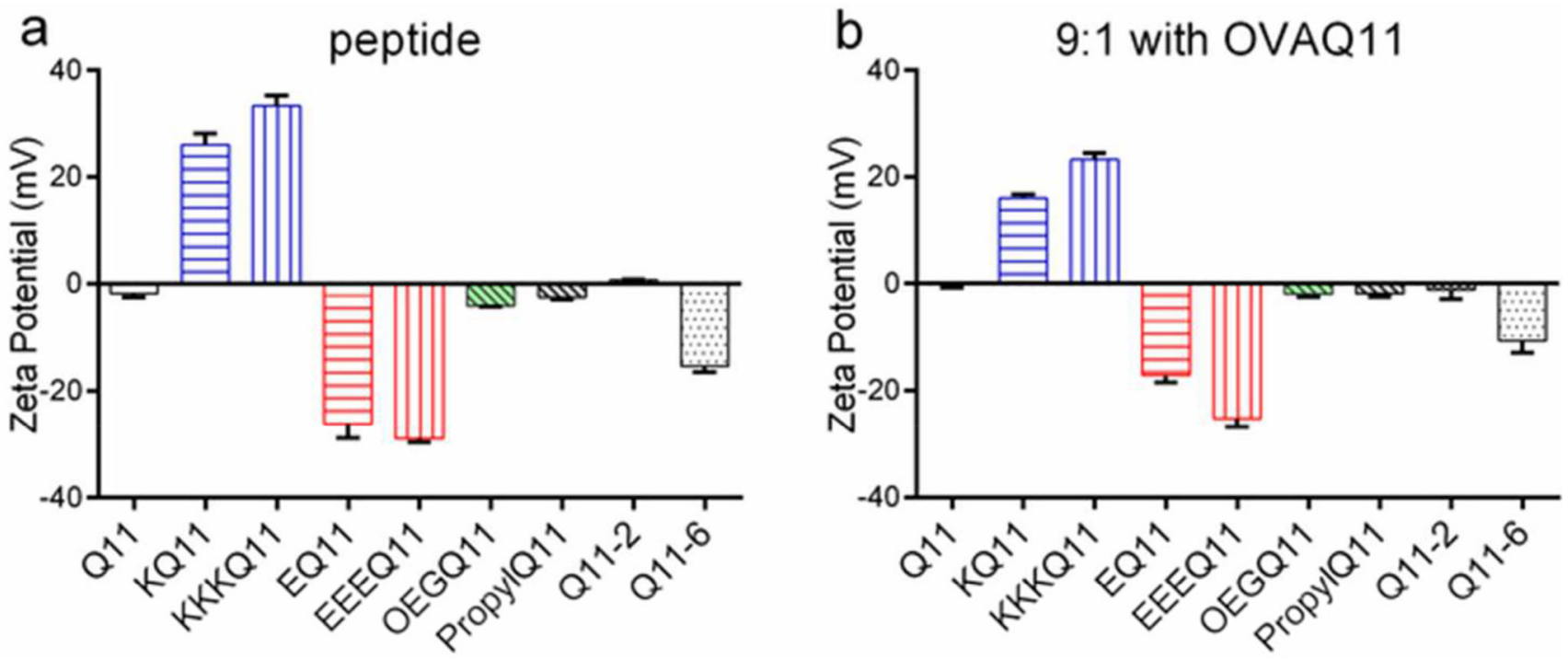

Figure 3. Zeta potentials of peptide nanofibers Lysine-terminated KQ11 and KKKQ11 produced nanofibers with positive zeta potentials, whereas glutamate-terminated EQ11 and EEEQ11 rendered nanofibers with negative zeta potentials $(a, b)$. Shown are zeta potentials of nanofibers containing one type of peptide (a) and those formed by mixing modified peptides 9:1 with OVAQ11 such that they contained 10 mol \% OVAQ11 (b). Dimethylation of all glutamine side chains (Q11-6) led to slightly negative surface potentials $(a, b)$, whereas other modifications did not significantly alter zeta potential. 

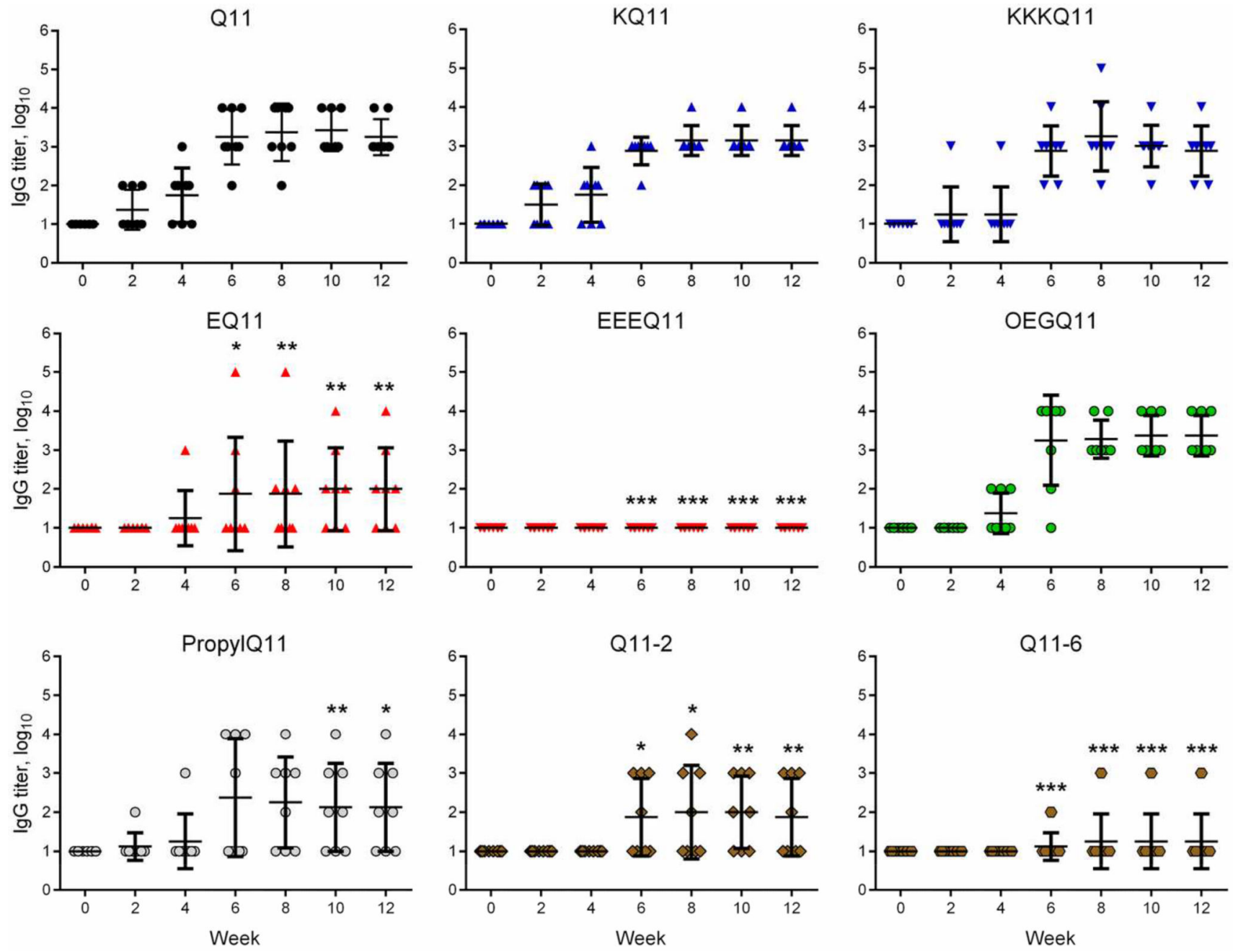

Figure 4. Antibody responses raised by nanofibers in mice

Nanofibers containing negatively charged Q11 variants showed significantly diminished (for EQ11) or abolished (for EEEQ11) titers. Mice were immunized subcutaneously with $100 \mu \mathrm{L}$ of $2 \mathrm{mM}$ nanofibers containing $90 \mathrm{~mol} \%$ of the modified peptides as indicated and $10 \mathrm{~mol} \%$ OVAQ11. This amounts to a dose of $20 \mathrm{nmol}(35 \mu \mathrm{g})$ of OVA epitope peptide. Mice were boosted once at week 4 with the same formulations. Serum total IgG titers were measured by ELISA. Data were combined from two independent experiments $(n=8$ total) and analyzed by one-way ANOVA and Dunnett's multiple comparison test (compared to Q11/OVAQ11 group at respective time points). ${ }^{*}: \mathrm{p}<0.05, * *: \mathrm{p}<0.01, * * *: \mathrm{p}<0.001$ 


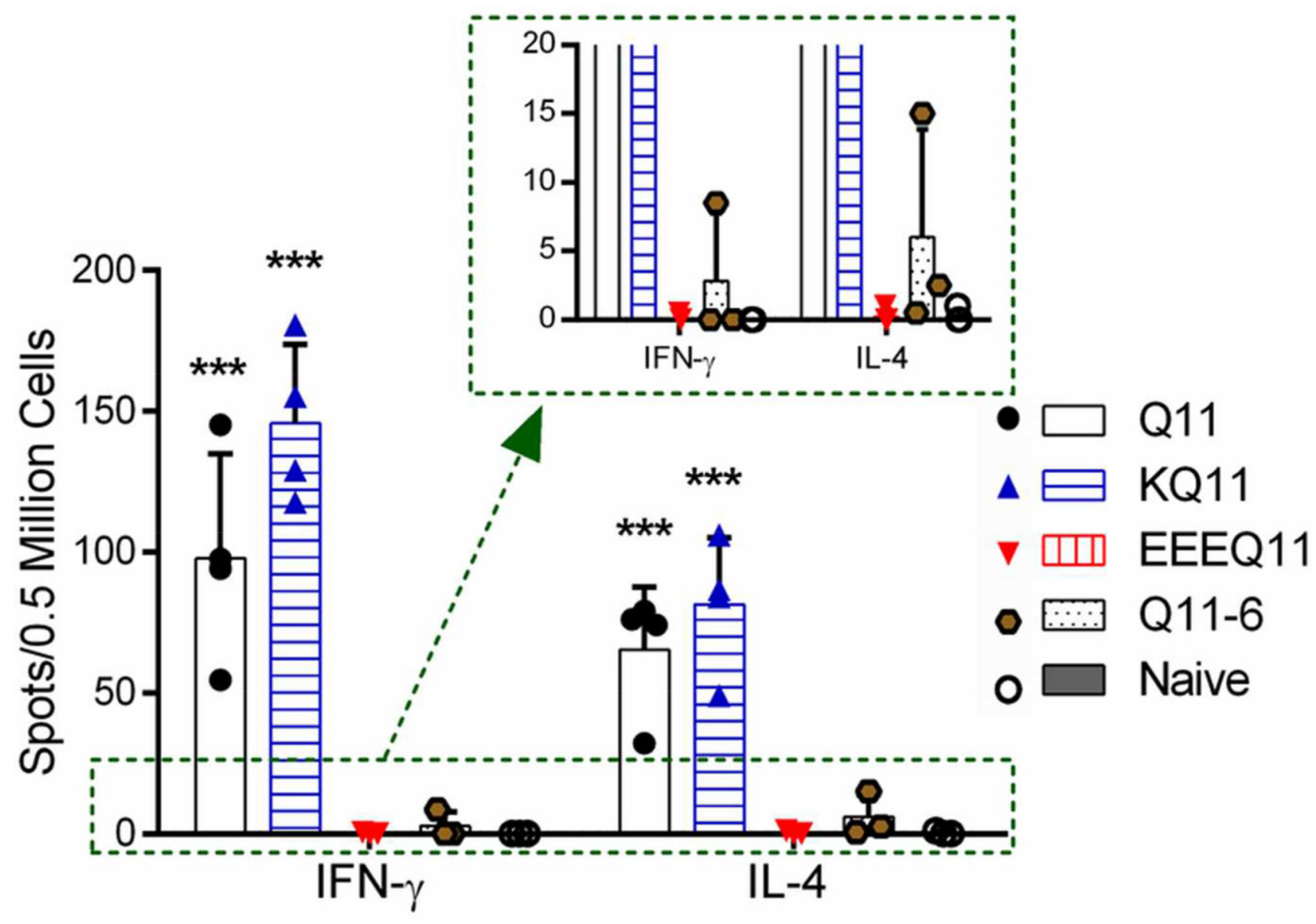

Figure 5. ELISPOT analysis of $T$ cell responses

Similar to antibody titers, $T$ cell responses were completely abolished against EEEQ11containing nanofibers. Mice were immunized subcutaneously with $100 \mathrm{uL} 2 \mathrm{mM}$ nanofibers containing $90 \mathrm{~mol} \%$ of the modified peptides as indicated and $10 \mathrm{~mol} \%$ OVAQ11 (20 $\mathrm{nmol} / 35 \mu \mathrm{g}$ OVA epitope) and then boosted at week 4 and week 12 with the same formulations. OVA-specific T cell responses were measured by ELISPOT at week 13. IFN- $\gamma$ or IL-4 secreting cells were quantified. The inset shows a magnified y-axis. Data were analyzed by two-way ANOVA and Dunnett's multiple comparison test (compared to naive control group). $* * *: \mathrm{p}<0.001$. 

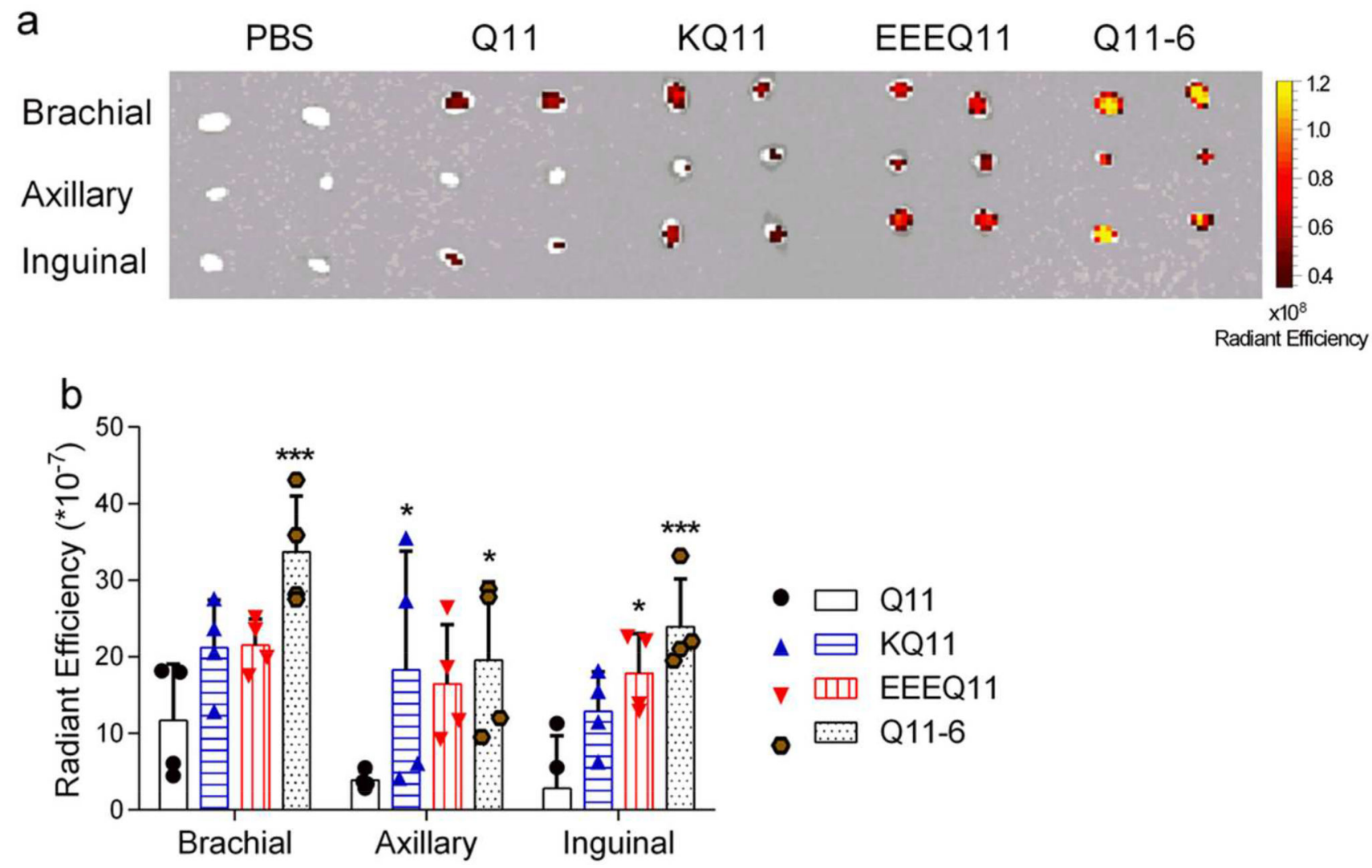

Figure 6. Surface potentials did not compromise lymphatic draining

Draining lymph nodes were collected at $24 \mathrm{~h}$ after immunization, imaged (a), and quantified (b). Mice were immunized subcutaneously with $100 \mathrm{uL}$ TAMRA-labeled nanofibers (1.8 $\mathrm{mM}$ peptide + 0.2 mM OVAQ11 + $0.02 \mathrm{mM}$ TAMRA-OVAQ11). Images shown were from one representative experiment $(n=2)$ and data plotted were combined from two experiments $(n=4)$ and analyzed by two-way ANOVA and Dunnett's multiple comparison test (compared to Q11 group). *:p<0.05, ***: $\mathrm{p}<0.001$. 

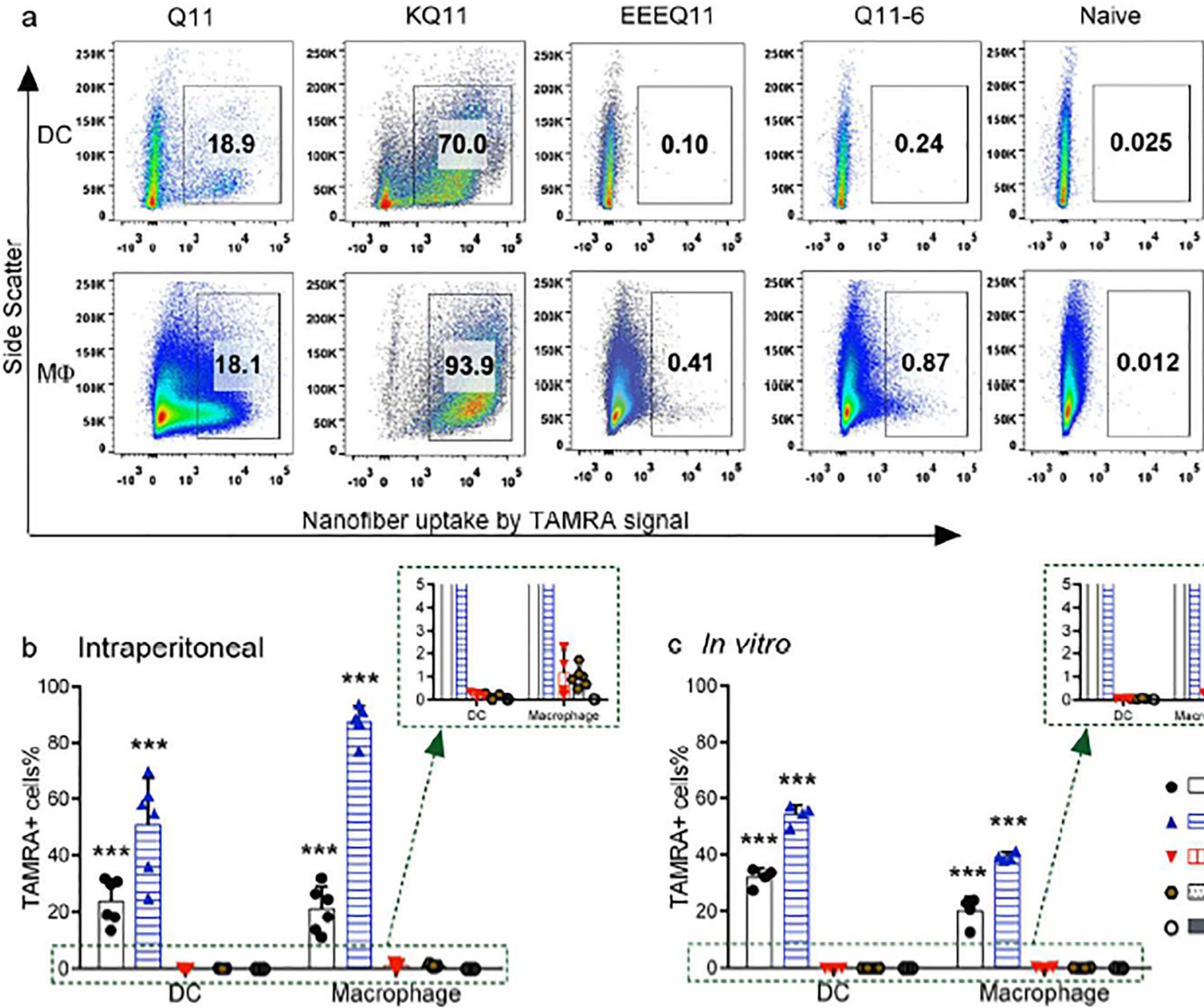

\section{c In vitro}

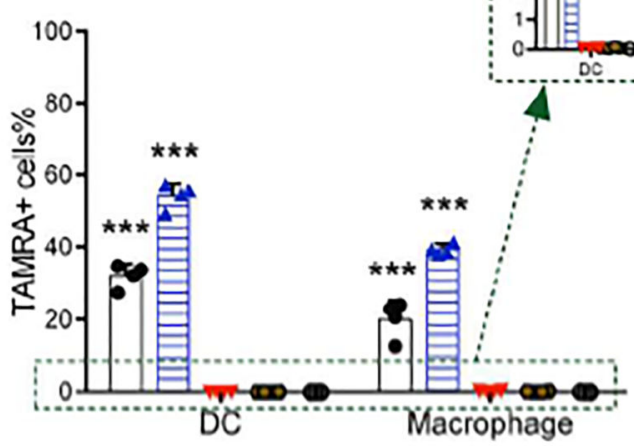

Figure 7. Nanofiber uptake by macrophages and dendritic cells was significantly modulated by surface potential, both in vivo and in vitro

Nanofibers with negative surface charge (containing EEEQ11 or Q11-6) had negligible uptake while nanofibers with positive surface charge (KQ11) were internalized to a greater degree than Q11, both in vivo (a, b) and in vitro $(\mathrm{c})$. Representative flow cytometry data for intraperitoneal injections are shown in (a) and quantified in (b), inset shows magnified yaxis. Quantified uptake data for in vitro cultures of macrophages and BMDCs are shown in (c). For intraperitoneal injections, mice received $100 \mathrm{uL}$ TAMRA-labeled nanofibers (1.8 $\mathrm{mM}$ peptide + $0.2 \mathrm{mM}$ OVAQ11 + $0.02 \mathrm{mM}$ TAMRA-OVAQ11; corresponding to an epitope dose of $20 \mathrm{nmol} / 35 \mu \mathrm{g}$ OVA epitope). Dendritic cells were defined as F4/80-/MHC class II high/CD11c+, macrophages were F4/80+, and the TAMRA signal was used to identify cells that had taken up the nanofibers. For in vitro delivery, Flt-3L-stimulated bone marrowderived cells were cultured with $0.1 \mathrm{mM}$ fluorescent peptide nanofibers. The same flow gating as above was used to distinguish DCs (over 97\% of the cells) from a minor fraction of macrophages, and to quantify the percentage of each population that took up the TAMRAlabeled nanofibers. Data shown were combined from two independent experiments $(b, n=6$; $\mathrm{n}=3$ for naive control) or from one independent experiment $(\mathrm{c}, \mathrm{n}=4)$. Data were analyzed by 
one-way ANOVA and Dunnett's multiple comparison test (compared to naive control group). $* * *: p<0.001$. 
a
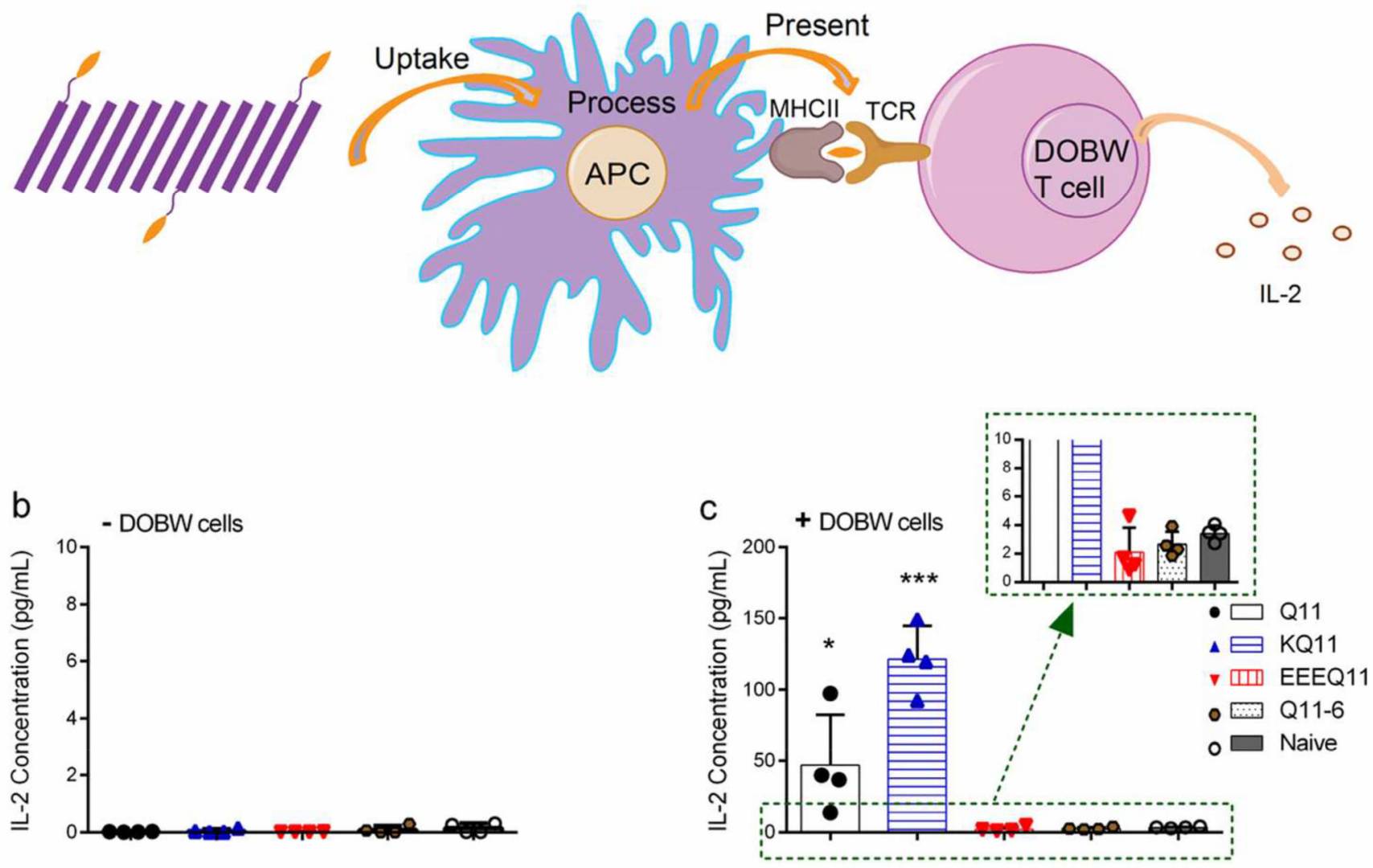

Figure 8. Antigen presentation depended strongly on nanofiber surface potential

Presentation of the OVA epitope in MHC class II molecules was measured using DOBW reporter T cells. Mice were immunized intraperitoneally with $100 \mathrm{uL} 2 \mathrm{mM}$ nanofibers containing $90 \mathrm{~mol} \%$ of the modified peptides as indicated and $10 \mathrm{~mol} \%$ OVAQ11 (20 nmol/35 $\mu \mathrm{g}$ OVA epitope dose), and APCs were recovered via IP lavage. These cells were co-cultured with DOBW cells, which secrete IL-2 upon encountering cellsurface MHC class II loaded with the OVA epitope (a). By themselves, cells from the IP lavage did not produce IL-2 (b). Negatively charged nanofibers (containing EEEQ11 or Q11-6) exhibited negligible presentation, whereas nanofibers containing positive KQ11 were presented more efficiently than Q11 (c, inset shows magnified y-axis). Data shown were from one representative experiment $(\mathrm{n}=4)$ and analyzed by one way ANOVA and Dunnett's multiple comparison test (compared to naive control group). *:p<0.05, ***: $\mathrm{p}<0.001$. 
a

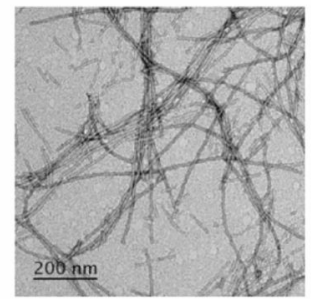

b

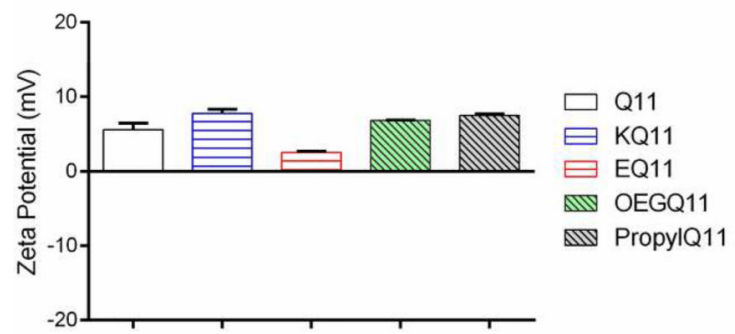

EQ11

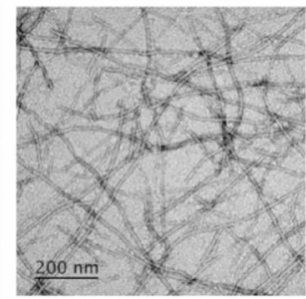

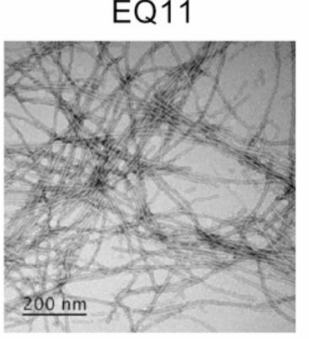

OEGQ11

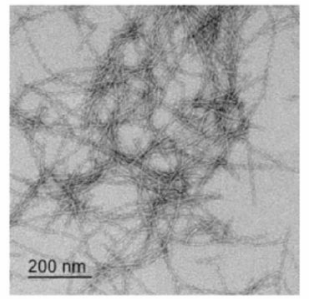

PropylQ11

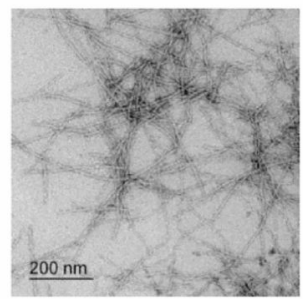

d
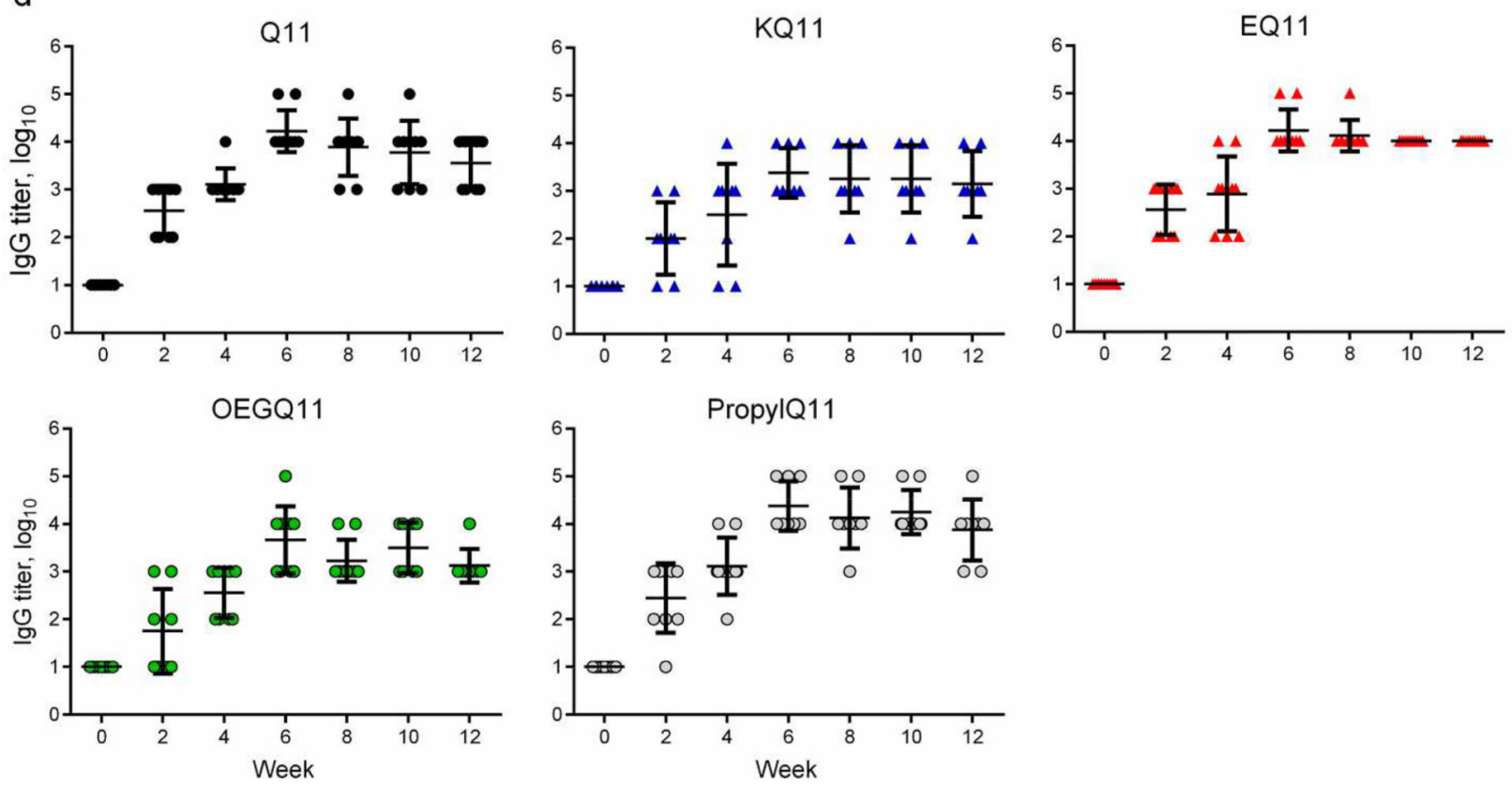

Figure 9. Nanofibers containing lower quantities of modified peptides retained more uniform zeta potentials and immunogenicity

Q11, KQ11, EQ11, OEGQ11, or PropylQ11 were co-assembled with OVAQ11 to produce nanofibers containing 33 mol\% modified peptide and 67 mol\% OVAQ11. All formed nanofibers (a), had slightly positive surface potentials (b), and had dominant $\beta$-sheet structure (c). Mice were immunized subcutaneously with $100 \mathrm{uL} 2 \mathrm{mM}$ nanofibers (134 $\mathrm{nmol} / 238 \mu \mathrm{g}$ OVA epitope dose). Mice were boosted at week 4. All nanofibers raised strong antibody responses (d). Data were combined from two independent experiments ( $\mathrm{n}=9$ total) and analyzed by one-way ANOVA and Dunnett's multiple comparison test (compared to Q11/OVAQ11 group). No statistical differences were found. 
Prime Boost 1 Boost 2 Boost 3
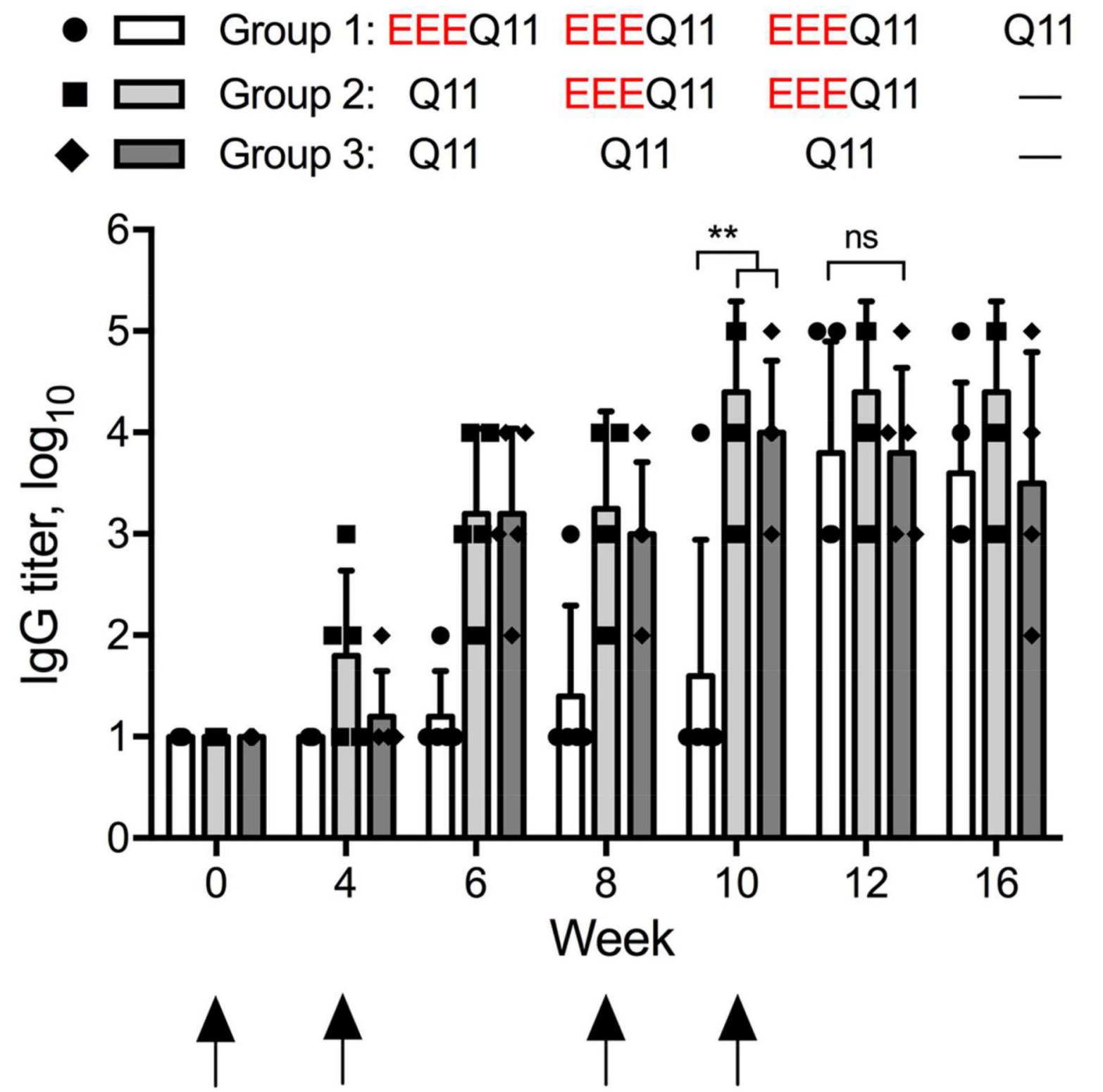

\section{Prime Boost 1}

Boost 2 Boost 3

Figure 10. Negatively charged nanofibers could not develop immune tolerance against subsequently delivered neutrally charged nanofibers, nor could they tolerize established immune responses

Mice were immunized subcutaneously with either neutral (Q11) or negatively charged (EEEQ11) nanofibers containing OVA and boosted at weeks 4, 8, and 10 with the formulations indicated in the figure (90 mol\% modified peptides and $10 \mathrm{~mol} \%$ OVAQ11, 2 $\mathrm{mM}$ total peptide, $100 \mu \mathrm{L}$ total volume, amounting to $20 \mathrm{nmol}(35 \mu \mathrm{g})$ of OVA epitope peptide). Repeated administration of EEEQ11 did not prevent subsequent immunogenicity of Q11 (Group 1), and immune responses established with Q11 were not tolerized by subsequent EEEQ11 administration (Group 2). Data shown were from one independent 
experiment ( $\mathrm{n}=5)$ and analyzed by one-way ANOVA and Dunnett's multiple comparison test (compared to Q11 group). **: p<0.01, ns: not significant. 


\section{Table 1}

Summary of peptides investigated

\begin{tabular}{lll}
\hline Peptide & Sequence & Property \\
\hline Q11 & QQKFQFQFEQQ & Base material \\
\hline KQ11 & K-SGSG-Q11 & Positive charge \\
\hline KKKQ11 & KKK-SGSG-Q11 & Positive charge \\
\hline EQ11 & E-SGSG-Q11 & Negative charge \\
\hline EEEQ11 & EEE-SGSG-Q11 & Negative charge \\
\hline OEGQ11 & $\mathrm{HO}\left(\mathrm{CH}_{2} \mathrm{CH}_{2} \mathrm{O}\right)_{2} \mathrm{CH}_{2} \mathrm{CH}_{2} \mathrm{C}(\mathrm{O})$-Q11 & Hydrophilicity \\
\hline Propy1Q11 & $\mathrm{CH}_{3} \mathrm{CH}_{2} \mathrm{CH}_{2} \mathrm{C}(\mathrm{O})-\mathrm{SGSG}-\mathrm{Q} 11$ & Hydrophobicity \\
\hline Q11-2 & QQKFQ*FQ*FEQQ & Structure breaking \\
\hline Q11-6 & $\mathrm{Q}^{*} \mathrm{Q} * \mathrm{KFQ}^{*} \mathrm{FQ} * \mathrm{FEQ}{ }^{*}{ }^{*}$ & Structure breaking \\
\hline
\end{tabular}

Q*: N, N-dimethyl Glutamine 


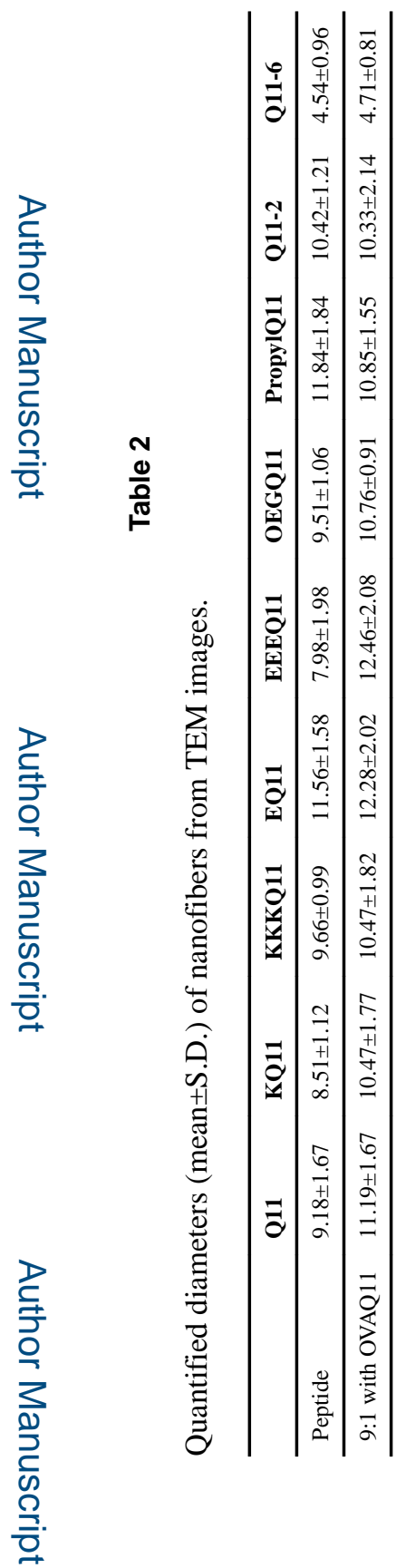




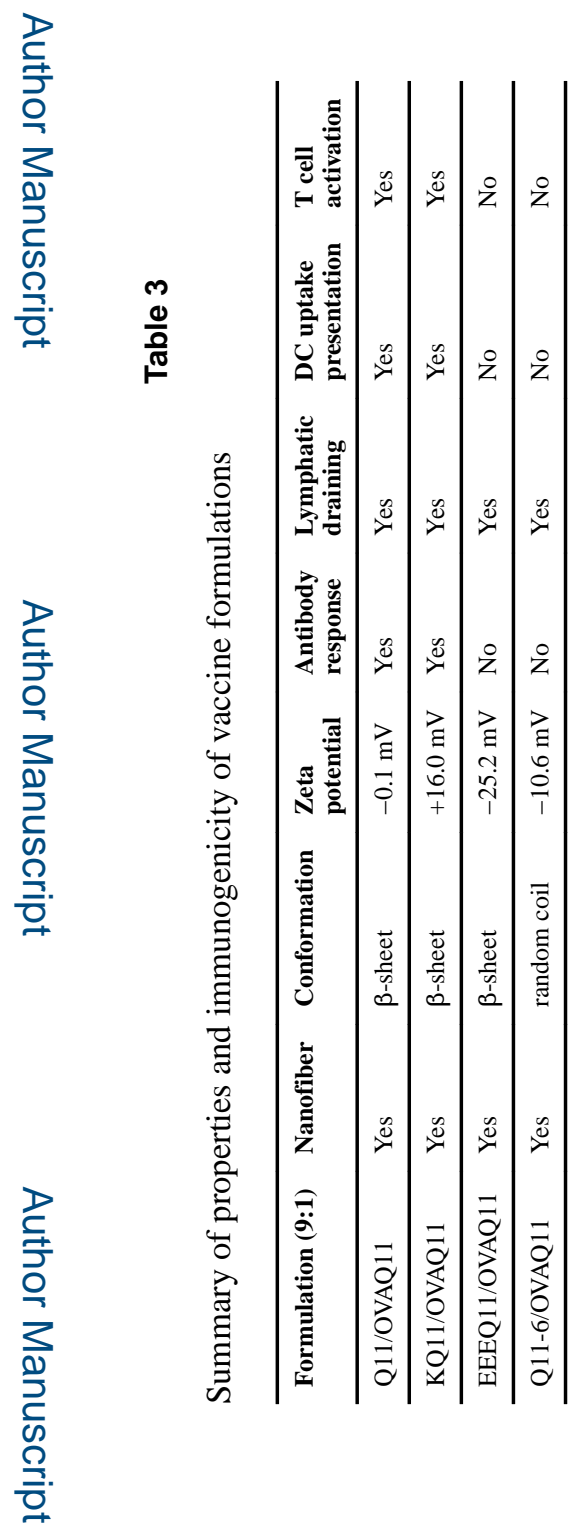

ACS Nano. Author manuscript; available in PMC 2018 April 03. 